\title{
PRIME
}

Verification of PUM's intervention logic: Insights from the PRIME toolbox

March 2018

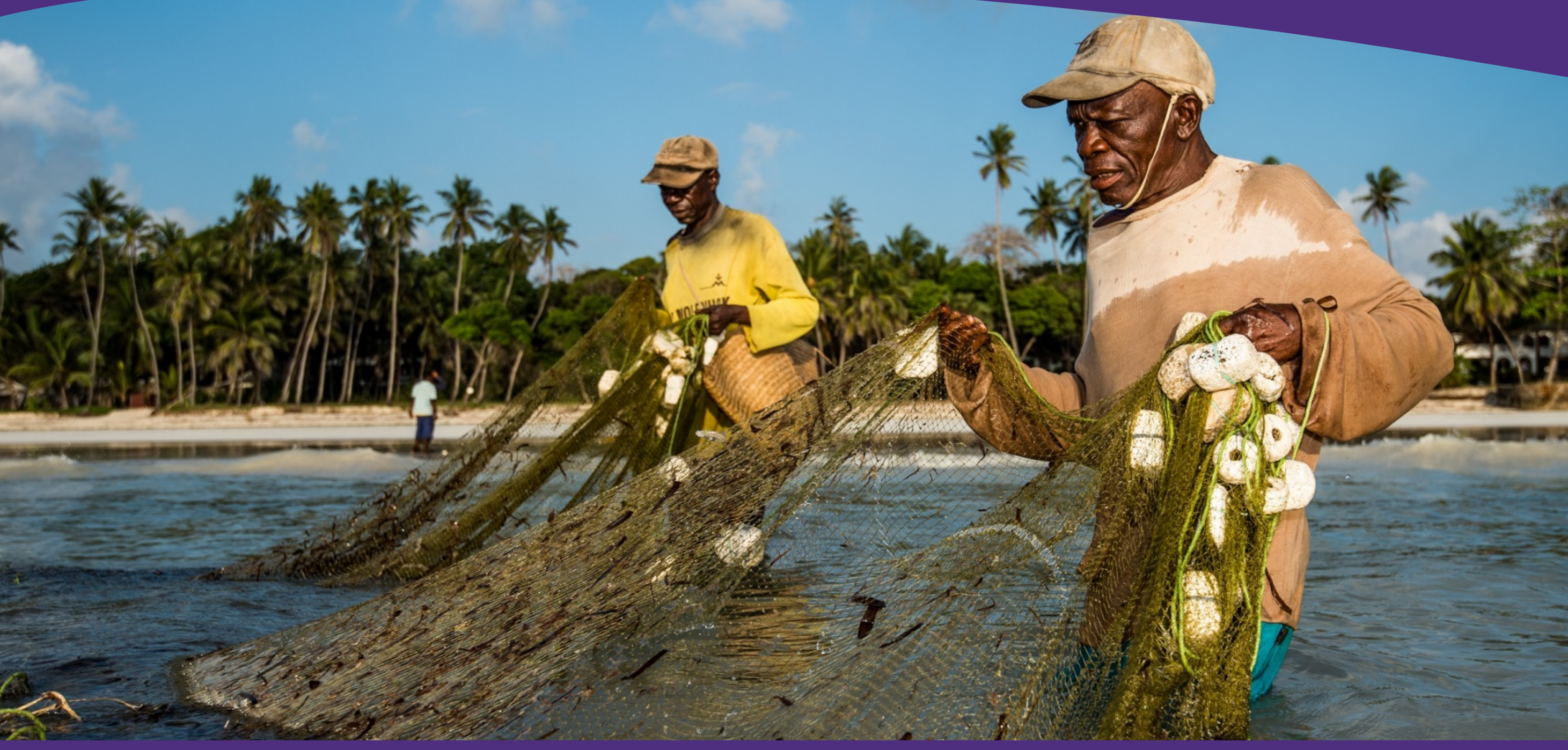





\section{Verification of PUM's intervention logic: Insights from the PRIME toolbox}

\section{March 2018}

Fédes van Rijn ${ }^{1}$, Giel Ton ${ }^{1,3}$, Karen Maas ${ }^{2}$, Haki Pamuk ${ }^{1}$, Job Harms ${ }^{2}$, Just Dengerink ${ }^{1}$ and Yuca Waarts ${ }^{1}$

With contributions by Carly Relou ${ }^{2}$, Birgit Vos ${ }^{2}$ and Frank Hubers ${ }^{4}$

${ }^{1}$ Wageningen Economic Research, ${ }^{2}$ Impact Centre Erasmus, ${ }^{3}$ Institute for Development Studies, ${ }^{4}$ Independent Research Consultant 
(C) 2018 Wageningen Economic Research

P.O. Box 29703, 2502 LS The Hague, The Netherlands, T +31 (0)70 33583 30, E communications.ssg@wur.nl, http://www.wur.eu/economic-research.

Wageningen Economic Research is part of Wageningen University \& Research.

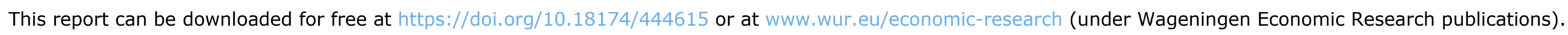

ISBN 978-94-6343-851-3

Cover photo: Opmeer Reports

\section{(cc) BY-NC}

For its reports, Wageningen Economic Research utilises a Creative Commons Attributions 3.0 Netherlands license.

(C) Wageningen Economic Research, part of Stichting Wageningen Research, 2018

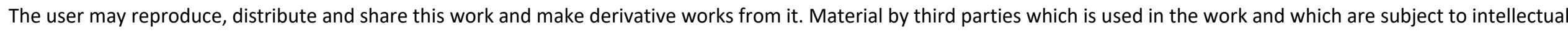

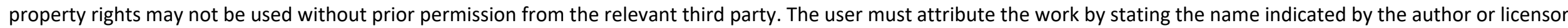
but may not do this in such a way as to create the impression that the author/licensor endorses the use of the work or the work of the user. The user may not use the work for commercial purposes.

Wageningen Economic Research accepts no liability for any damage resulting from the use of the results of this study or the application of the advice contained in it.

Wageningen Economic Research is ISO 9001:2008 certified. 


\section{Contents}

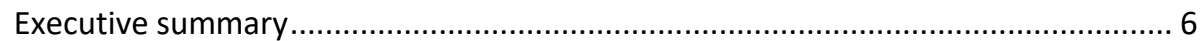

Chapter 1: Evaluating PUM's impact through PRIME ............................................. 8

Chapter 2: PUM's activities and supported SMEs .................................................. 9

Chapter 3: Mixed method design for learning and accountability ........................... 13

Chapter 4: PUM's contribution to SME knowledge and practices........................... 18

Chapter 5: PUM's contribution to SME performance .............................................. 24

Chapter 6: Enabling factors for effectiveness of PUM support ............................... 28

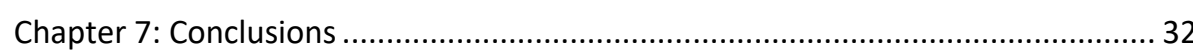

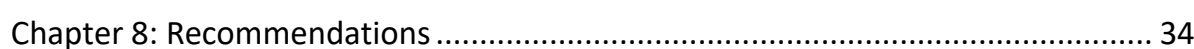

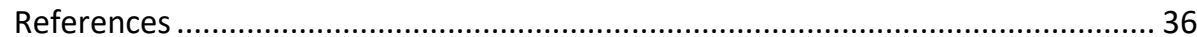




\section{Executive summary}

PUM aims to contribute to sustainable economic development by enabling Dutch senior experts to transfer knowledge to small and medium enterprises in developing countries, thereby improving their performance. PUM Netherlands senior experts aim to contribute to sustainable economic development in developing countries by improving the performance of small and medium enterprises (SMEs). PUM wants to achieve this aim by linking Dutch senior experts to SMEs in developing countries to stimulate knowledge transfer, help SMEs to apply for grants and promote business links with Dutch companies. With increased knowledge levels, new business links and access to grants, SMEs are expected to improve their business practices. That, in turn, should lead to higher turnover and profit, better employment, increased sustainability and more business with Dutch companies. Each of these outcomes is expected to contribute to sustainable and inclusive economic growth.

The PRIME Partnership between PUM, CBI, Wageningen Economic Research and the Erasmus School of Economics monitors impact of PUM and CBI support to SMEs. The PRIME partnership was established in 2013 to develop and implement a methodology to monitor and evaluate the real-time impact of private-sector development support by PUM and the Centre for the Promotion of Imports from developing countries (CBI). PRIME stands for Pioneering Real-time Impact Monitoring and Evaluation and is a research partnership between Wageningen Economic Research and the Erasmus School of Economics, supported by PUM and CBI. The PRIME partnership assesses the impact of PUM and CBI support to SMEs.

PRIME has developed a data collection system and an innovative mixed methods design to verify the assumptions behind PUM's theory of change. The PRIME partnership has developed a data collection system that makes it possible to verify the assumptions behind PUM's theory of change and assist PUM in monitoring progress on its objectives. PRIME uses an innovative parallel mixed method design ${ }^{1}$ that integrates the quantitative analysis of administrative data and online surveys with the qualitative analysis of interviews held with PUM beneficiaries, experts and stakeholders in five countries: Peru, Bolivia, Uganda, Bangladesh and Indonesia. Our evaluation focuses on the impact of PUM missions to SME knowledge (immediate outcomes), practices (intermediate outcomes) and performance (ultimate outcomes). PRIME collected data over the period between 2014 and 2017.

The PUM intervention logic is largely consistent with the literature. By providing knowledge to SMEs, PUM aims to help SMEs improve their business practices and ultimately enhance their performance in terms of sales, productivity and employment creation. The literature suggests that providing business training and consultancy to small and medium-sized enterprises imparts valuable knowledge to firms in developing countries, which in turn helps them to improve their business practices and subsequently generate gains in productivity. The literature also suggests that business consultancy has the best chance of improving a firm's performance when expert missions result in knowledge transfer in those domains where the SMEs are lagging behind.

\section{PUM has generated positive changes in SMEs' knowledge and business practices} The results show that PUM has contributed to one or more changes in knowledge and business practices for $90 \%$ of the businesses they support. PUM's contributions were most significant in three areas: (1) efficient ways of organising the business, (2) leading, planning and organising the business, and (3) ideas about new products and services. Furthermore, PUM experts were much appreciated for their technical expertise on production processes and knowledge on market requirements, and for their ability to generate new ideas for investments and business organisation. The 
data show a correlation between PUM's perceived contribution to business knowledge and the number of business practices adopted, confirming PUM's assumption that the knowledge acquired by PUM experts helps to improve SMEs' business practices. PUM's perceived contribution to better practices is quite evenly distributed in terms of business size and sector, with only small differences between sectors and business sizes.

PUM's contribution to better practices has helped to improve SMEs' performance. The data show that the support PUM provides to improve business practices has translated into better business performances. The number of SMEs reporting an increase in profit is on average two to three per cent higher for those benefitting from PUM's contribution to better practices than for those who did not receive support from PUM. Typically, a company's sales increased by about $€ 11,000$ (34\%) following PUM support compared to sales before PUM support. The effect of PUM's support on employment varies according to the focus of the missions. Missions that focus on efficient ways of organising the business increase employment in the business by $33 \%$, while missions that focus on financial management reduce employment by $18 \%$. However, missions that focus on financial management target companies that have financial problems and have to cut costs.

PUM's impact on SMEs' performance differs significantly between sectors and country income group. The data show that sales and employment growth is stronger in the tourism \& catering sector than in the agriculture \& horticulture and food \& beverage sectors. The sales for a typical SME operating in the tourism \& catering sector doubles following PUM missions, while the increases in sales of SMEs in the food \& beverage and agriculture $\&$ horticulture sectors are about $32 \%$ and $48 \%$ after PUM missions. Moreover, PUM missions are more successful at improving the sales performance of businesses in least-developed countries. Following PUM missions the sales of a median PUM firm from a least-developed country increases by $61 \%$ compared to the sales before PUM missions, while this increase is $25 \%$ for the median PUM firm from a lower middle-income country.
The effectiveness of the support depends to a large extent on the qualities of the expert, the timing of the mission, and the communication between the expert and the SME manager. PUM's interventions are not always successful in boosting a firm's performances. During the cases studies, several firms indicated that the expert that was dispatched did not have the specific knowledge or expertise to help the firm with the particular problem it was facing. In other cases, the language barrier prevented effective communication. The lack of (advanced) Spanish-speaking experts was mentioned by both SMEs and local representatives as a major issue that impacts the effectiveness of PUM experts in Latin America.

Results from this study vary significantly between different type of companies and under different conditions, pointing to important enablers of PUM's effectiveness. Some conditions seem to be more enabling for larger impacts, and some types of firm seem better suited to the support modalities used by PUM. Important enablers of PUM's effectiveness are the presence of strong business support organisations (BSOs). BSOs work to improve the business environment for public sector policy and investment programmes. According to the supported firms, another key enabler was access to finance to implement certain changes in business practices. Finally, both PUM's staff and policymakers consider more coordination with other Dutch privatesector support organisations to be important enablers of effectiveness.

PRIME results confirm PUM's theory of change as they demonstrate PUM's contribution to knowledge transfer and better practices, which have increased exports, profits and employment. Summarising the results of this study, we can conclude that PUM positively influenced knowledge transfer and better business practices among firms supported by PUM. Not only do the improved knowledge levels correlate with improved business practices, but the data also show that better business practices improve business performances. Firms supported by PUM have significantly increased their sales and profits, and the missions that have focused on improving business organisation have had a positive effect on employment. PUM's support has also proven to complement existing support: the level of expertise offered by PUM experts is considered to be unavailable in the local market. 


\section{Chapter 1: Evaluating PUM's impact through PRIME}

PRIME responds to the need for credible impact estimates of private-sector support. The PRIME partnership was established in 2013 to develop and implement a methodology to monitor and evaluate the real-time impact of private-sector development support by PUM and CBI. There were three reasons for establishing the PRIME partnership. First, the necessity of reporting the impact of private-sector support on common impact indicators (jobs, revenues and scale). Second, the difficulty of going beyond before-after measurements and the use of comparison groups. Third, a desire for meaningful impact evidence which can be used during the implementation of programmes, for both accountability and learning purposes.

PRIME stands for Pioneering Real-time Impact Monitoring and Evaluation. PRIME stands for Pioneering Real-time Impact Monitoring and Evaluation and is a research partnership between Wageningen Economic Research and the Erasmus School of Economics, supported by PUM (Netherlands senior experts) and CBI (Centre for the Promotion of Imports from developing countries). The PRIME partnership assesses the impact of PUM and CBI's support to SMEs.

PRIME collected data to verify PUM's theory of change. The PRIME partnership has collected data to verify the assumptions behind PUM's theory of change and assists PUM in monitoring progress on its objectives. Our evaluation focuses on the impact of missions to improve SME knowledge (immediate outcomes), practices (intermediate outcomes) and performance (ultimate outcomes), as about $75 \%$ of PUM's activities are related to supporting SMEs through one-on-one coaching. PRIME collected data over the period between 2014 and 2017.
SMEs in developing countries are constrained in terms of knowledge. By providing knowledge to SMEs, PUM aims to help SMEs improve their business practices and ultimately enhance their performance in terms of sales, productivity and employment creation. Indeed, the literature suggests that many SMEs in developing countries have limited knowledge regarding best business practices and consequently have much lower productivity than firms in developed high-income nations. ${ }^{2}$ As a result, providing business training and consultancy to small and medium-sized enterprises imparts valuable knowledge to firms in developing countries, which in turn helps them to improve their business practices and subsequently generate gains in productivity. $^{3,4,5,6}$

The academic literature supports PUM's theory of change. Overall, the literature suggests that PUM's activities have the potential to improve a firm's performance, provided the expert missions actually result in knowledge transfer in those domains where SMEs are lagging behind. We now turn to a description of PUM's activities and the theory of change regarding the expected effects of its activities.

The structure of this report follows the key elements of PUM's theory of change. This report verifies whether these assumptions about effectiveness actually hold in practice. Chapter 2 describes the theory of change and PUM's activities in more detail. Chapter 3 presents the methods used to verify the theory of change. Chapter 4 reports on the findings related to PUM's efforts to improve SMEs' knowledge and practices. Chapter 5 shows how the changes in knowledge and practices have helped to improve SMEs' performances. After describing the barriers to and enablers of effectiveness in Chapter 6, this report presents its conclusions and recommendations for PUM in Chapter 7. 


\section{Chapter 2: PUM's activities and supported SMEs}

Figure 2.1

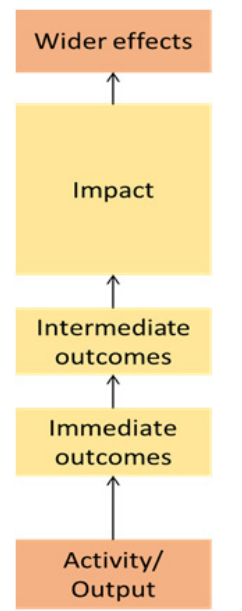

PUM's theory of change. PUM's activities also include support to BSOs

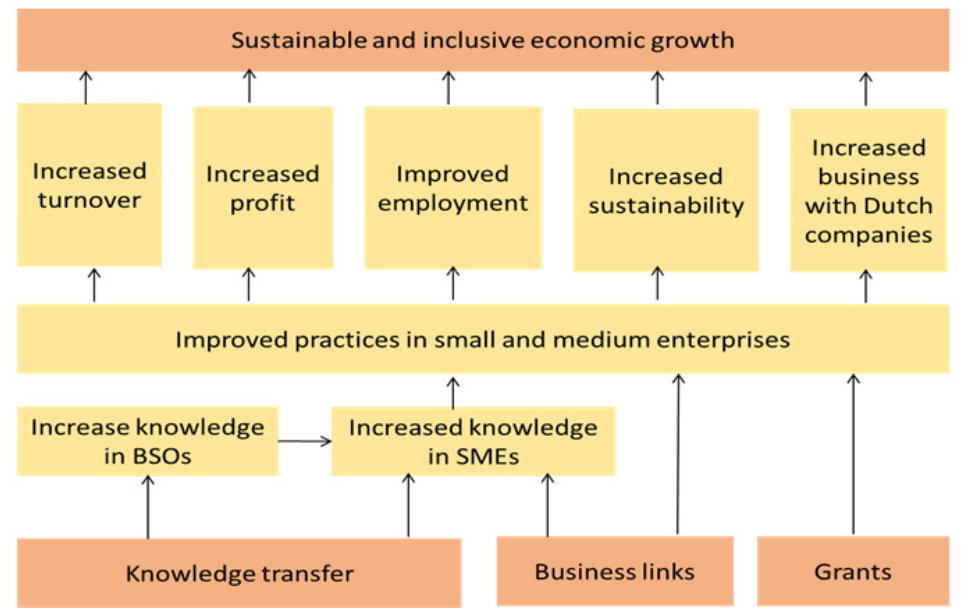

The aim of PUM Netherlands senior experts. PUM Netherlands senior experts contributes to sustainable economic development in developing countries by improving the performance of small and medium enterprises (SMEs). PUM achieves this by linking Dutch senior experts, many of whom are former managers from Dutch firms, to SMEs in developing countries to stimulate knowledge transfer, help SMEs to apply for grants and promote business links with Dutch companies. With increased knowledge levels, new business links and access to grants, SMEs are expected to improve their business practices. That, in turn, will lead to higher turnover and profit, better employment, increased sustainability and more business with Dutch companies. Each of these outcomes is expected to contribute to sustainable and inclusive economic growth.
PUM's mission aims to improve SMEs' business practices in a range of areas, depending on the needs of the firms that are being supported. As figure 2.2 shows, most PUM missions focus on improving the product or service quality (3.7 out of 5); a few missions focus on financial management (2.3 out of 5); and some focus on the requirements of (inter)national buyers (2.2 out of 5). Apart from these three areas, the focus of PUM's missions are quite evenly distributed among the support areas.

\section{Figure 2.2 Focus of PUM missions according to intensity of support (2015-2017)}

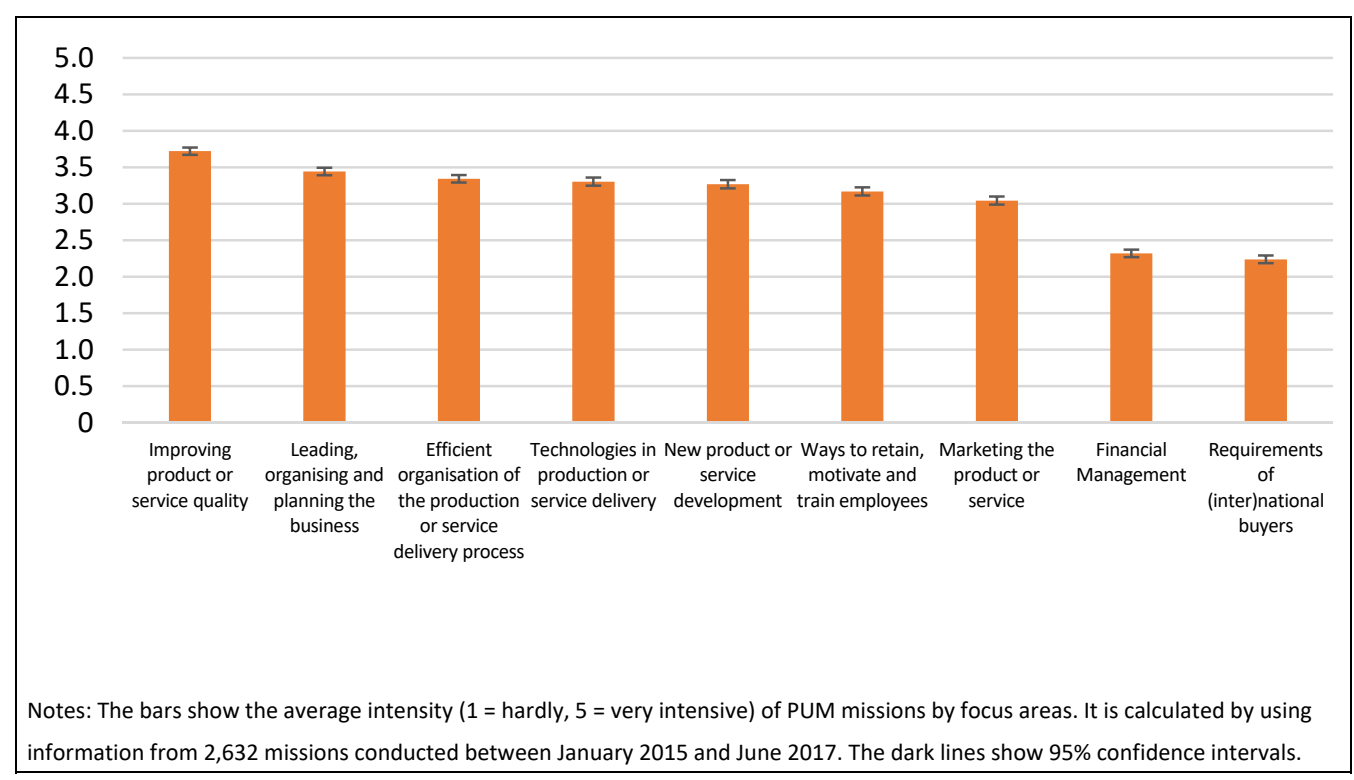


PUM supports 1,950 one or two-week expert missions every year in a wide variety of sectors and countries. Between 2013 and 2016, PUM dispatched between 1,900 and 2,000 senior experts to SMEs each year. Most firms hear about PUM via local representatives (90\%), who are the key contact persons representing PUM in a particular (part of the) country. Around $70 \%$ of the firms were visited by one support mission from PUM, 15\% were visited by two missions and the remaining $15 \%$ of the firms were visited by more than two missions. Most missions last 1-2 weeks, and the majority of firms were in contact with PUM prior to the mission.
In total 7,749 missions were conducted between 2013 and 2016, and 700 business links were established. The average cost of these missions was $€ 5,295$. Figure 2.3 shows that some countries have a much higher density of PUM missions than others. In Africa, Kenya, Uganda, South Africa, Rwanda and Ghana have high influx of PUM experts. In South America, Colombia, Bolivia and Peru receive the majority of missions, while in Asia Indonesia, Bangladesh, Vietnam and Nepal are popular. In Eastern Europe PUM is most active in Albania, Bosnia and Macedonia.

Figure 2.3 The geographic distribution of SMEs supported by PUM, PRIME datasets

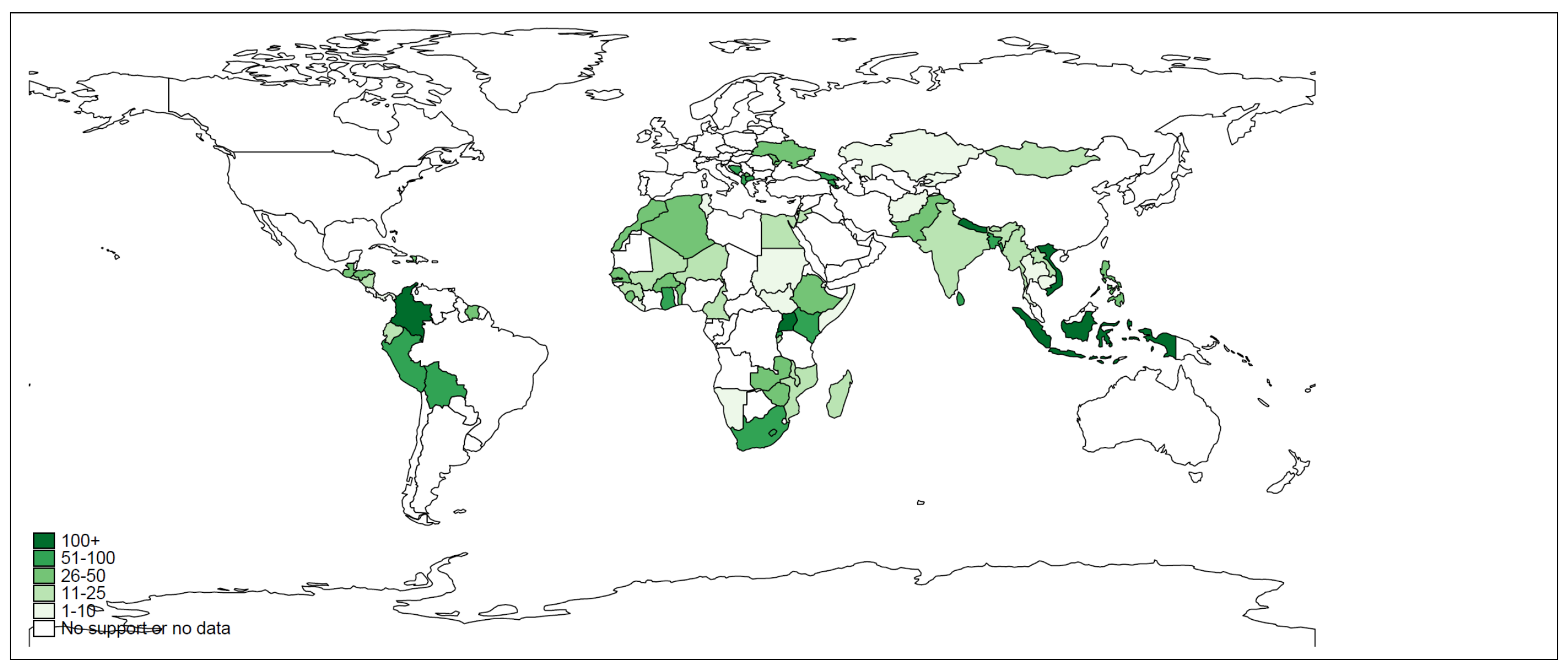


The largest share of PUM support goes to SMEs in the industry \& engineering sector $(42 \%)$, closely followed by services $\&$ trade $(36 \%)$ and agriculture $(22 \%)$.

Forty-two per cent of the firms supported by PUM operate in the industry \& engineering sector. Another third (36\%) operate in the services \& trade sector, while $22 \%$ are active in the agricultural sector. Within these sectors, PUM is bigger in some subsectors than in others. As figure 2.4 below illustrates, half of PUM's support goes to only four subsectors: food \& beverage production (16\%), tourism, hotels \& catering (13\%), stockbreeding \& fisheries (11\%), and agriculture \& horticulture (11\%). PUM's potential to contribute depends on the type of sector in which it operates. For example, manufacturing and agricultural firms typically have more scope to substitute labour for capital than service sector firms. Therefore, PUM's effect on employment may be different in the service sector than in agriculture or industry.

\section{Figure 2.4 Sectoral distribution of PUM-supported firms, PRIME data}

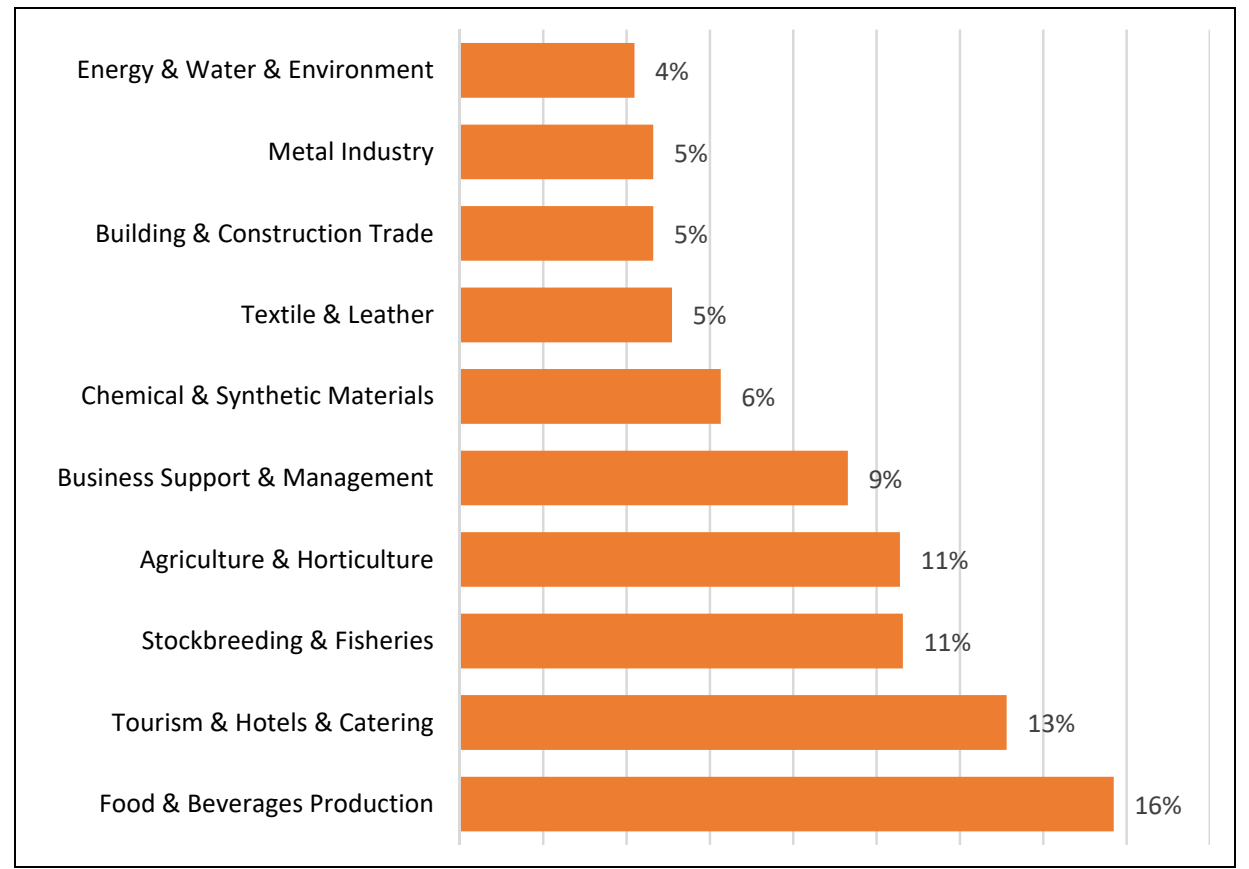

Most support goes to lower middle-income countries in Africa and Asia, shifting slightly to LDCs and low-income countries.

PUM supports firms in four regions: Africa, Asia, Latin America and Eastern Europe. Most firms supported by PUM are based in Africa (36\%) and Asia (30\%), while fewer firms are supported in Latin American and European countries. In total, $28 \%$ of the firms receiving support are from least-developed countries (LDCs). Most of PUM's support is concentrated in lower middle-income countries (39\%) and upper middleincome countries (22\%). In the period 2014-2017, however, PUM's support shifted from middle-income countries to least-developed and lower-middle income countries: the percentage of firms receiving support in LDCs and low-income countries has increased from $35 \%$ to $51 \%$.

This shift may have two contradictory implications. The levels of business knowledge and practices are generally lower in LDCs and low-income countries, which means there is more room for improvement: companies there are more likely to substantially improve their knowledge and practices due to PUM's support. On the other hand, investment climate conditions in LDCs and low-income countries are less favourable for expanding businesses. These less favourable conditions may hamper the transformation of knowledge into investment and business growth.

The majority of firms supported by PUM are small (10-50 employees). The size of firms supported by PUM varies greatly: from 2 employees to 9,800. The majority of these firms (62\%) can be defined as small - having between 10 and 50 employees. This is not surprising given PUM's application criteria, which requires firms to have between 10 and 250 employees. However, $8 \%$ of the firms receiving support employ fewer than 10 employees. The size of a firm is an important characteristic to take into account when analysing the effect of private-sector support. In fact, the academic literature shows that larger firms, on average, have better business skills. ${ }^{7}$

This raises the question of whether PUM's support is more effective among smaller firms whose baseline levels of business skills are lower, or among slightly larger firms which might already have a somewhat better business skill set to begin with. On the one hand, smaller firms might benefit more from PUM's advisory services because 
they may need to learn more. On the other hand, larger firms could be better positioned to integrate the newly-obtained insights into their business practices.

Figure 2.5 Distribution of PUM-supported firms by firm size, PRIME data

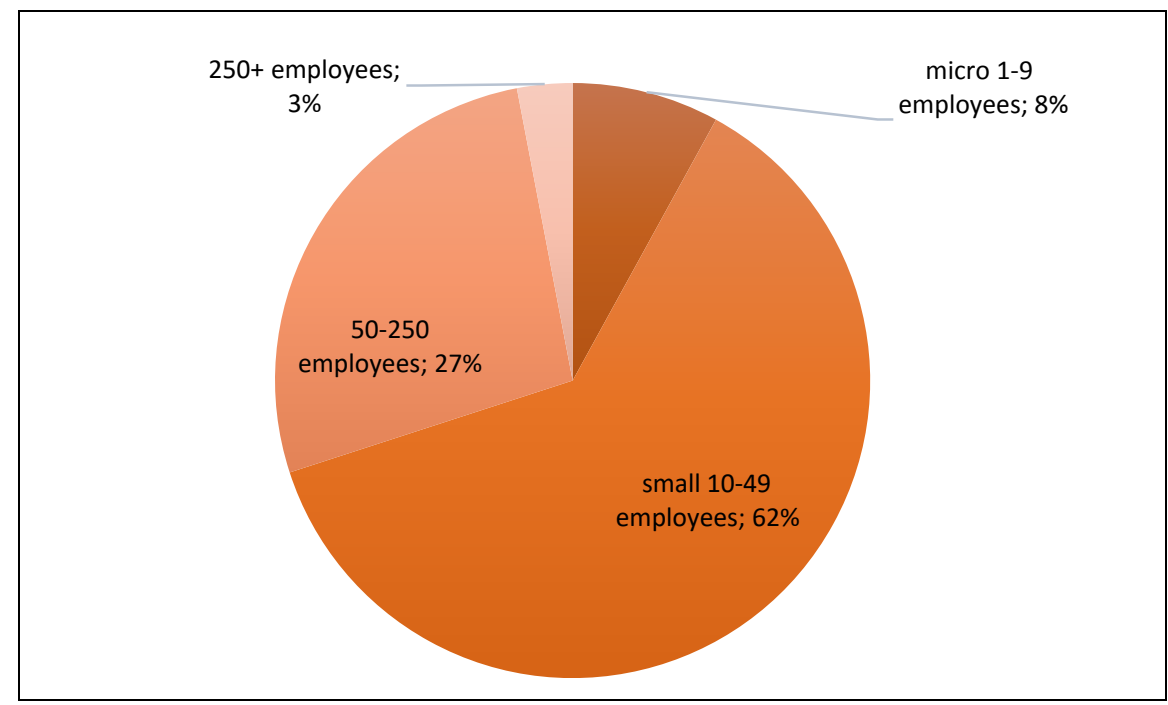

More than half of the firms supported by PUM are fully or partially owned by males. The majority of firms supported by PUM are owned by males (65\%). A significant portion is owned by females (24\%). The academic literature suggests that women in developing countries are often drawn into entrepreneurship due to the lack of opportunities in other income-generating activities (Nichter and Goldmarkt, 2009).

Furthermore, women in developing countries have typically enjoyed lower levels of education than their male counterparts, which can make it more challenging for them to efficiently operate firms. This is reflected by lower levels of sales and profitability in female-owned firms in developing countries. ${ }^{8}$ Since 2011, PUM has had a strategy group on gender to improve its reach of female-owned and female-managed firms. PUM reduces the barriers to reaching these women in various ways, for example by increasing the number of female experts and local representatives.
Figure 2.6 Distribution of PUM-supported firms by gender of the business owner PRIME data

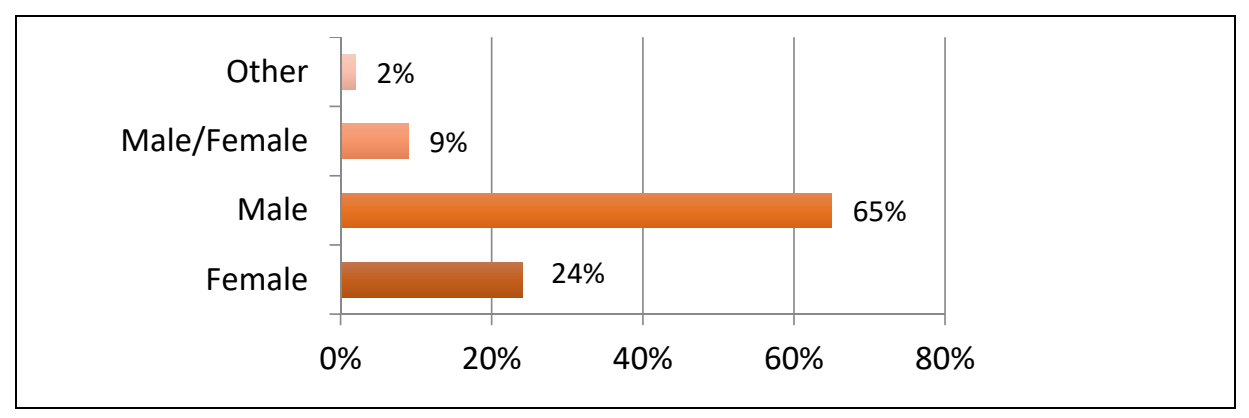

Most firms supported by PUM find it challenging to access finance. Over half of the firms report that when they require capital or an investment to finance business activities the situation (figure 2.7 ) is either 'hard' (34\%) or 'very hard' (22\%). Particularly firms in least-developed countries and low-income countries report challenges in accessing finance. For instance, the percentage of firms from developing countries with 'either difficult or very difficult' access to finance is $65 \%$; however, the percentage of firms from upper middle-income countries with 'either difficult or very difficult' access to finance is $45 \%$. In particular, firms that do not have access to finance might find it challenging to invest and grow their businesses.

Figure 2.7 Distribution of PUM-supported firms by access to finance, PRIME data

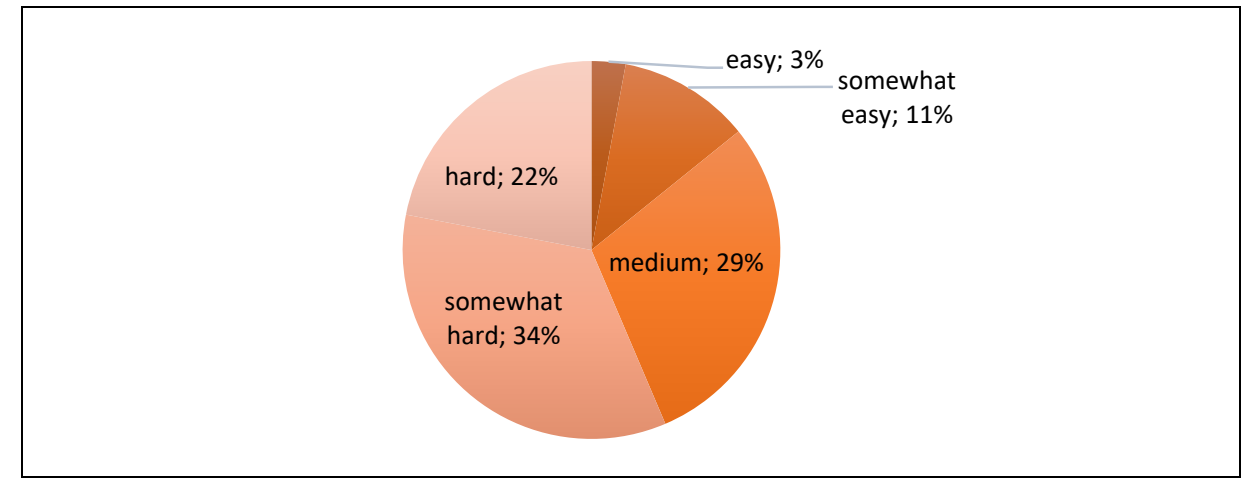




\section{Chapter 3: Mixed method design for learning and accountability}

To verify PUM's contribution to sustainable economic development, we developed a mixed method design. This required us to specify and verify the main causal impact pathways that explain how a certain type of support activity is expected to effectively increase turnover, employment and sectoral innovation/upgrading processes. We used both quantitative and qualitative methods to verify these impact pathways. For the quantitative research, we used administrative data and yearly online surveys to companies and experts to assess the extent to which PUM's support contributed to changes in the firm's business practices. ${ }^{1}$ Parallel to this, we conducted qualitative case studies in five countries. In these case studies, we held semi-structured interviews with PUM beneficiaries, experts and other key stakeholders. Most of these interviews were text-coded for use in the cases study reports and the overall synthesis. Another qualitative component was the literature review on current evidence regarding SME support.

The mixed methods design enabled us to triangulate findings. The qualitative literature review was used to develop the quantitative online surveys and establish the focus of the case studies. Moreover, the qualitative literature review helped us to correlate the results to wider trends in private-sector development (PSD) and SME support. The qualitative case study material helped us to interpret the results from the quantitative administrative data and online surveys; the results of these quantitative and qualitative approaches enabled us to triangulate the findings, thereby strengthening the validity of the results.
The research components are nested. The three research components differ in scope and depth, to make sure the study captures the dynamics of programme implementation at the field level, while also ensuring that the study results are sufficiently representative.

Figure 3.1 Overview of the PRIME research methodology

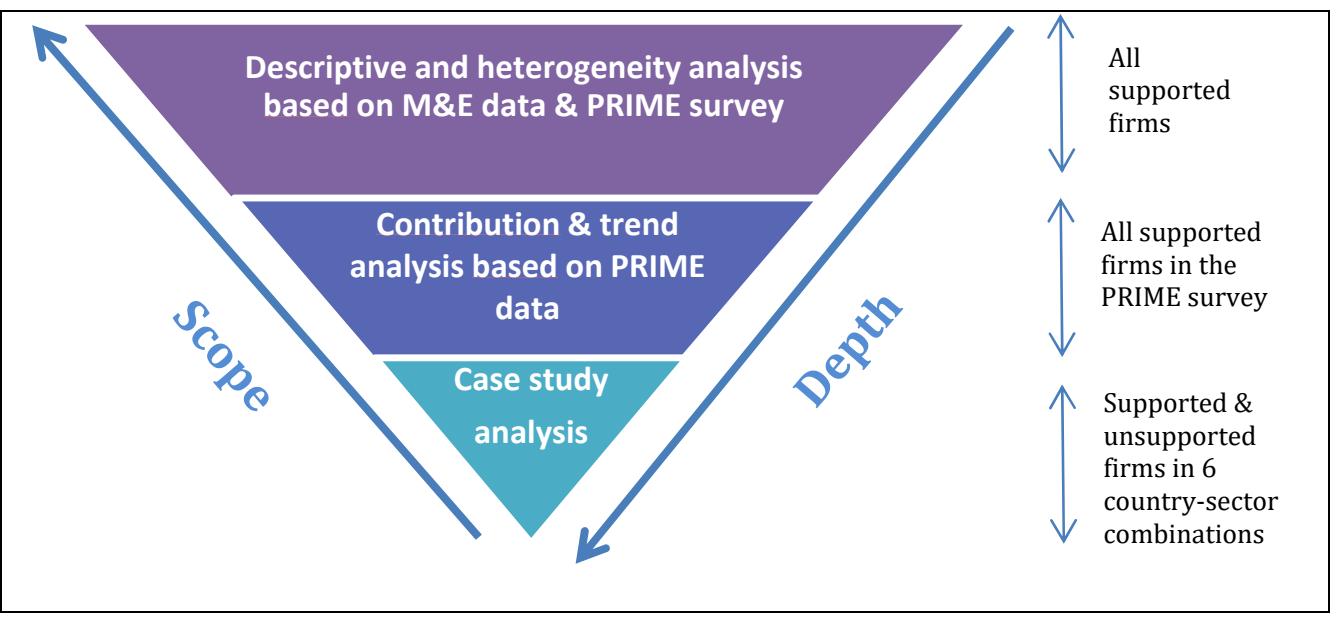

\footnotetext{
${ }^{1}$ An extensive description of the quantitative research methodology can be found in PRIME policy brief 3.
} 
PRIME used PUM's administrative data from 5,353 firms that were visited by a mission between January 2013 and June 2017 to develop the online survey. Moreover, these data were used to control the firms' baseline characteristics. The following information was used from the M\&E system: the name of the contact person and contact details, the gender of the owner, the employment level of the business when missions were conducted, the sector and country of the firm, as well as the date and the duration of the mission.

\section{Figure $3.2 \quad$ Distribution of respondents per year of support}

\begin{tabular}{ll} 
Cohort & Number of firms \\
\hline 2013 & 328 \\
\hline 2014 & 589 \\
\hline 2015 & 578 \\
\hline 2016 & 797 \\
\hline 2017 & 487 \\
\hline
\end{tabular}

PRIME (online) surveys were conducted in July 2015, 2016 and 2017. Firms that were visited by an expert up to three years before the survey date received an invitation to complete the online surveys. ${ }^{2}$ Out of 5,353 firms that were invited to complete the survey, in total 2,779 of the firms that were visited by missions from January 2013 to June 2017 completed the PRIME surveys. So the overall response rate is about $52 \%$.

There were three types of questions in the online survey. The first type of question focused on perceived knowledge and practices, asking businesses to self-assess the change in their knowledge and practices in eight areas (see figure 3.3). Additionally, they were asked about PUM's contribution to these changes over the past 12 months.

\footnotetext{
2 Some firms received an invitation multiple times. For instance firms that received a mission in 2015 received an invitation to fill in the PUM survey in 2015, 2016 and, 2017. So the number of invitations includes firms that received an invitation to fill in the survey multiple times.
}

Figure 3.3 Perceived knowledge and practices areas

\begin{tabular}{|c|c|}
\hline 1. Financial management & $\begin{array}{l}\text { 5. Quality requirements of (inter)national } \\
\text { buyers, }\end{array}$ \\
\hline $\begin{array}{l}\text { 2. Effects of the business on the } \\
\text { environment }\end{array}$ & 6. Ideas about new product $\&$ services \\
\hline $\begin{array}{l}\text { 3. Marketing techniques to increase sales of } \\
\text { your product or service }\end{array}$ & $\begin{array}{l}\text { 7. Leading, planning and organising the } \\
\text { business }\end{array}$ \\
\hline $\begin{array}{l}\text { 4. Ways to retain, motivate and train } \\
\text { employees }\end{array}$ & $\begin{array}{l}\text { 8. Efficient ways of organising the production } \\
\text { process or service delivery }\end{array}$ \\
\hline
\end{tabular}

The second type of question in the online survey focused on observable business practices and included ten questions that together form a proxy of the overall quality of the business management (see figure 3.4).

Figure 3.4 Observable business practices

\begin{tabular}{|c|c|}
\hline $\begin{array}{l}\text { 1. Financial statements verified by control } \\
\text { outside the company }\end{array}$ & 6. All employees have business contract \\
\hline $\begin{array}{l}\text { 2. Keeping financial records through an } \\
\text { external firm/specialised software }\end{array}$ & $\begin{array}{l}\text { 7. Systems and policies in place to monitor and } \\
\text { ensure workers' safety }\end{array}$ \\
\hline 3. Having a marketing plan & $\begin{array}{l}\text { 8. Systems to learn about the clients' opinions } \\
\text { on its products and services }\end{array}$ \\
\hline 4. Having a business website & 9. A documented quality assurance system \\
\hline 5. Having promotion materials & $\begin{array}{l}\text { 10. A system to monitor effects on the } \\
\text { environment }\end{array}$ \\
\hline
\end{tabular}

Finally, the third element of the survey focused on performance-related questions. These questions focused on sales, changes in profit compared to the previous year, and permanent and temporary employment. 
Information about the firm's situation before the missions was collected through recall questions: questions on the situation one or two years before a firm was visited by an expert. Using the information from recall questions, we were able to compare the performance of PUM firms before and after the missions and estimate PUM's impact on business performance. Figure 3.5 summarises by year and cohort as well as the structure of the data collected through PRIME surveys.

\section{Figure 3.5 Cohort and data structure}

$\begin{array}{llllll}\text { Year of first } & \text { Cohort } 1 & \text { Cohort } 2 & \text { Cohort } 3 & \text { Cohort } 4 & \text { Cohort } 5 \\ \text { mission } & (2013) & \text { 2014) } & \text { (2015) } & \text { (2016) } & \text { (2017) }\end{array}$

Year of data

collection

\begin{tabular}{llllll}
\hline $\mathbf{2 0 1 1}$ & Before (recall) & No data & No data & No data & No data \\
\hline $\mathbf{2 0 1 2}$ & Before (recall) & Before (recall) & No data & No data & No data \\
\hline $\mathbf{2 0 1 3}$ & Support & Before (recall) & Before (recall) & No data & No data \\
\hline $\mathbf{2 0 1 4}$ & Follow up & Support & Before (recall) & Before (recall) & No data \\
\hline $\mathbf{2 0 1 5}$ & Follow up & Follow up & Support & Before (recall) & Before (recall) \\
\hline $\mathbf{2 0 1 6}$ & Follow up & Follow up & Follow up & Support & Before (recall) \\
\hline $\mathbf{2 0 1 7}$ & No data & Follow up & Follow up & Follow up & Support \\
\hline
\end{tabular}

In addition to the administrative data and the online surveys, PRIME did qualitative case study research in five different countries. ${ }^{3}$ These five cases reflect the diversity of the sectors and economic conditions in which PUM operates. Making use of interviews with beneficiaries, experts and other key stakeholders in the different sectors and countries, these case studies provide an understanding of the programme's effects in terms of business knowledge, practices and firm performance. Furthermore, the case studies searched for contextual factors that shape the programme's effects and look at the additionality of PUM's support to other programmes and donor activities. Figure 3.7 on the next page shows a map with the locations for the case studies and a brief description of each case study.

\footnotetext{
3 An overview of the case study reports can be found on http://www. primepartnership.nl/countries/. The methodology
} for the case studies is summarised in this polciy brief and this conceptual framework.

This report synthesises a wide variety of data collection and data analysis methods. Based on the sources presented above, the following analyses were carried out to help answer the research questions regarding PUM's contribution to improve SMEs' business practices.

\section{Figure 3.6 Data sources and types of analysis}

Data source

Administrative

data

PRIME surveys

PRIME surveys

Literature review - Qualitative review of the relevant literature available on private-

Interviews with

SMES

BSOs, external

experts
- Contribution scores based on self-assessment questions

- Testing of contribution scores based on observable practices questions

- Testing the relationship between contribution scores and business performance sector and SME support

Testing the relationship between contribution scores and business Transcription and interview summaries are text-coded using Altas. software

- Selection of illustrative examples and divergent cases to reflect the impact pathways

- Exploratory, interpretative analysis of barriers to and enablers of effectiveness and additionality of the support 


\begin{tabular}{|c|c|c|c|c|}
\hline $\begin{array}{l}\text { Peru, natural ingredients. In Peru we } \\
\text { focus on the sector of high-value } \\
\text { agricultural products and on those SMEs } \\
\text { that are involved in the supply of semi- } \\
\text { finished products. Most High-Value } \\
\text { Agricultural Products (HVAPs) have higher } \\
\text { market values than traditional cereal } \\
\text { grains and export crops. Globally, high- } \\
\text { value agricultural products cover an } \\
\text { important part of the support provided by } \\
\text { CBI and PUM. This sector was especially } \\
\text { interesting given the linkage to the } \\
\text { producer level supply side and CSR issues } \\
\text { involved. }\end{array}$ & $\begin{array}{l}\text { Bolivia, tourism. PUM and CBI have both } \\
\text { supported more than } 20 \text { SMEs and several } \\
\text { BSOs in the last decade in the tourism } \\
\text { sector (including travel agencies and } \\
\text { hotels), some of which received support } \\
\text { from both organisations. Key focus areas } \\
\text { were the quality of business support } \\
\text { organisations, willingness to pay for } \\
\text { support and required investments, } \\
\text { appropriate selection of firms and the } \\
\text { additionality of the support. }\end{array}$ & $\begin{array}{l}\text { Uganda, coffee and agriculture. This case } \\
\text { focused on the activities of } \mathrm{CBI} \text { in the } \\
\text { Ugandan coffee sector and the activities of } \\
\text { PUM in the agricultural sector in Uganda. } \\
\text { In the period 2014-16, } 178 \text { missions were } \\
\text { implemented by PUM in Uganda, with } \\
\text { concentration in (i) agri- and horticulture, } \\
\text { (ii) food and beverages, (iii) stockbreeding } \\
\text { and fishery. }\end{array}$ & $\begin{array}{l}\text { Bangladesh, IT. This case focused on the } \\
\text { activities of CBI and PUM in the IT sector } \\
\text { in Bangladesh. This case stood out in } \\
\text { terms of the programme's focus on high- } \\
\text { tech products and services rather than } \\
\text { commodities, and the support towards } \\
\text { helping companies shift from a purely } \\
\text { service-based business model towards } \\
\text { higher value addition product } \\
\text { development. }\end{array}$ & $\begin{array}{l}\text { Indonesia, fishery and aquaculture. This } \\
\text { case focused on the activities of CBI and } \\
\text { PUM in the fishery \& aquaculture sector in } \\
\text { Indonesia. Given the large geographical } \\
\text { scope, the field visits focused on the } \\
\text { activities in Java. Due to the intricate } \\
\text { connections between this sector and the } \\
\text { environment, there was a particular focus } \\
\text { on the topic of environmental } \\
\text { sustainability. }\end{array}$ \\
\hline
\end{tabular}


PRIME determined contribution scores for eight areas of business management. Contribution scores measure PUM's contribution to knowledge and practices by using self-assessment data on PUM's perceived impact on knowledge and practices in about eight different areas. Figure 3.8 below shows how the contribution scores were calculated based on two self-assessment questions. Through regression analysis, we tested whether a high contribution score is associated with higher exports, employment creation and profits.

Figure 3.8 Questions used to determine contribution scores

\begin{tabular}{llll}
$\begin{array}{l}\text { How has your company's } \\
\text { knowledge/practices changed over } \\
\text { the past } \mathbf{1 2} \text { months? }\end{array}$ & $\begin{array}{l}\text { Has PUM } \\
\text { influenced this } \\
\text { change? }\end{array}$ & $\begin{array}{l}\text { Rank PUM } \\
\text { contribution }\end{array}$ & $\begin{array}{l}\text { PUM contribution } \\
\text { score, (0-100) }\end{array}$ \\
\hline Strong decrease & - & 0 & 0 \\
\hline Decrease & - & 0 & 0 \\
\hline No change & - & 0 & 0 \\
\hline Increase & No effect & 0 & 0 \\
\hline Strong increase & No effect & 0 & 0 \\
\hline Increase & Very little & 1 & 13 \\
\hline Strong increase & Very little & 2 & 25 \\
\hline Increase & Some & 3 & 38 \\
\hline Strong increase & Some & 4 & 50 \\
\hline Increase & Quite a bit & 5 & 63 \\
\hline Strong increase & Quite a bit & 6 & 75 \\
\hline Increase & A lot & 7 & 88 \\
\hline Strong increase & A lot & 8 & 100 \\
\hline
\end{tabular}

Throughout the text, we interpret these contribution scores as follows:

- Contribution score=0: There is no increase in knowledge or no PUM contribution

- Contribution score 1-50: There is an increase in knowledge (practice) and PUM influenced this increase slightly or to some degree.

- Contribution score 51-100: There is an increase in knowledge (practice) and PUM influenced the increase substantially or very substantially
The PRIME methodology anticipated several potential threats to the validity of the research design. First of all, the observed differences in outcome of firms (e.g. sales trends) cannot be directly attributed to PUM's support. Other exogenous variables including prices, inflation and other economic and political circumstances - can influence outcomes such as SME/firm practices or profit. The PRIME method partially controls for these trends by including fixed year effects in the regression. Moreover, the observed differences in time may vary for firms with different sizes from different countries and sectors. Therefore, to control for these factors we used a regression that includes business size, sector, country and start year of the programme, year, trust and risk behaviour of the SMEs. A second potential threat to validity is measurement error, especially recall bias. A recall bias can be present when there is a structural difference between the estimates of the outcomes in the present and the outcomes in the past. Under- or over-reporting the results in one of the years may paint an overly optimistic or overly pessimistic picture of PUM's support. The PRIME methodology, however, makes it possible to compare a firm's reporting in subsequent surveys and could consequently reduce the threat to validity related to recall bias.

The PRIME methodology is robust but has its limitations. No methodology is perfect. In the PRIME research we struggled with several inherent limitations. First, the estimation of the programme's effects is based on data from participating firms and does not make a comparison with non-supported firms. Although we addressed this methodological challenge by accounting for pre-programme trends and using the variation in treatment intensity in the contribution score, we cannot discount the possibility that part of the estimated effect simply reflects growth that firms would have undergone anyway, in the absence of PUM's support. Moreover, the research did not make a cost-efficiency assessment. Finally, this cost-efficiency is highly conditional on the preferred outcome indicator, which is a normative, political decision. 


\section{Chapter 4: PUM's contribution to SME knowledge and practices}

PUM contributes to change in one or more areas of business management in about $\mathbf{9 0 \%}$ of the SMEs they support. We calculated PUM's average contribution to knowledge and practices by using the average score of eight contribution scores for eight knowledge (practice) areas. Reflecting on changes that have taken place over the past 12 months in their firms, on average $24 \%$ (29\%) of these businesses report a positive change in knowledge (practices), which was much or very much influenced by PUM, and 66\% (63\%) of these businesses report a positive change in knowledge (practices), which was influenced little or somewhat by PUM (figure 4.1). ${ }^{4}$ The percentage of businesses that report no positive change in knowledge (practices) and/or no PUM influence on change is $10 \%(8 \%)$. This implies that PUM has contributed to at least one area of business management in about $90 \%$ of the businesses they supported over the past 12 months. After considering the specific focus of PUM in these missions, the percentage of firms that have witnessed positive change in knowledge and practices and are much or very much influenced by PUM increased by about four percentage points on average. Interestingly, the distribution of the contribution scores among each of the areas of business management is very similar through the years (2015-2017). This reflects the robustness of the measure.
Figure 4.1 PUM contribution to change in knowledge and practices in at least one area

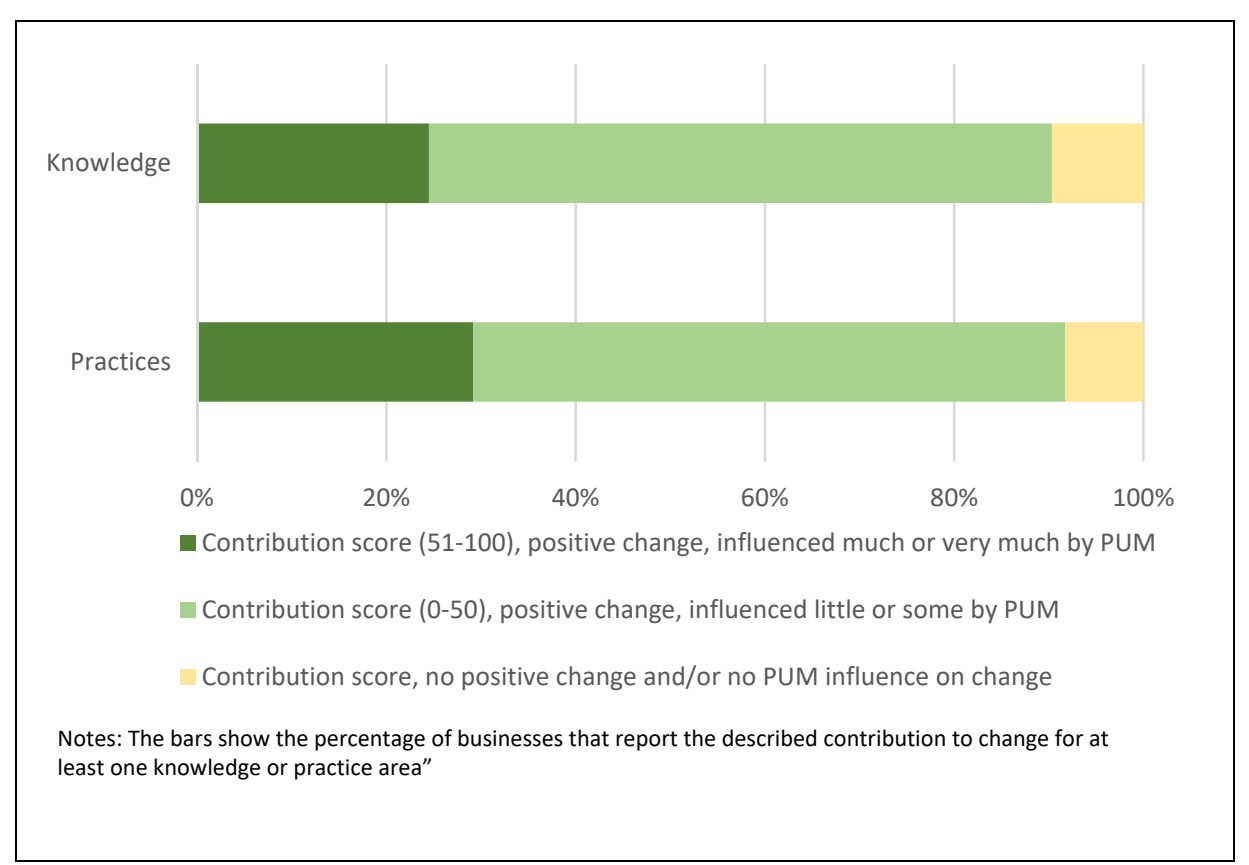

\footnotetext{
4 The information on PUM's contribution to change in knowledge and practice areas are from three different surveys conducted in 2015, 2016 and 2017. Scores for each area are very similar through the years; t-tests for each area show that the scores are not statistically different for these years. We therefore pooled data from all of the years for the analysis in figures 3.1 and 3.2 .
} 


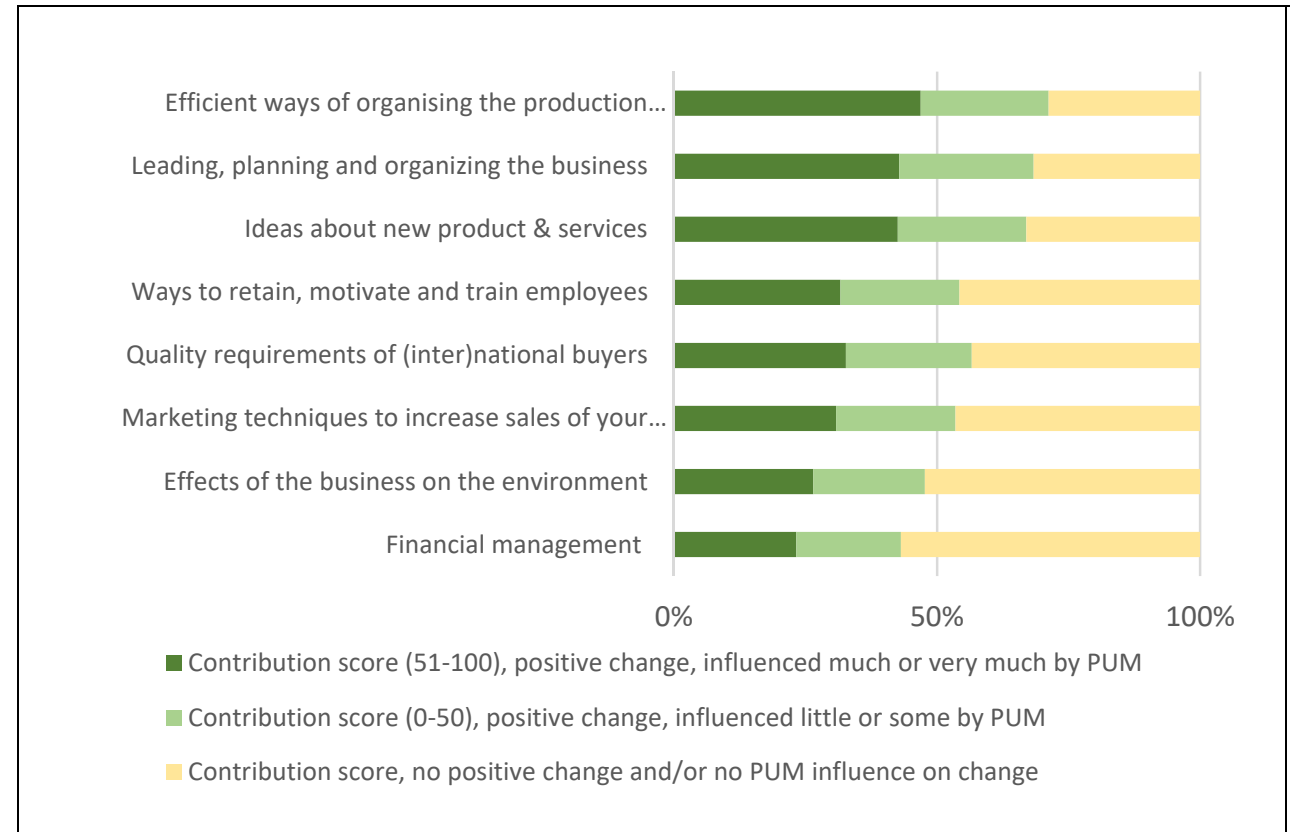

The three areas where PUM contributes most in terms of knowledge and practices are: i) efficient ways of organising the business, ii) leading, planning and organising the businesses, and iii) ideas about new products and services. The data show that missions generally focus on certain areas, such as the efficient organisation of the business and leading, planning, and organising the business. The share of businesses that report a positive change in knowledge and practices and much or very much influence on that change by PUM is more than $40 \%$ for i) efficient ways of organising the business, ii) leading planning and organising the businesses, and iii) ideas about new products and services. Financial management and the effects of the business on the environment score the lowest: positive change (very) substantially influenced by PUM is less than $25 \%$ for both areas. PUM's missions focus less on these areas compared to others.
Efficient ways of organising the production...

Leading, planning and organizing the business

Ideas about new product $\&$ services Quality requirements of (inter)national buyers Ways to retain, motivate and train employees

Marketing techniques to increase sales of

Effects of the business on the environment

Financial management

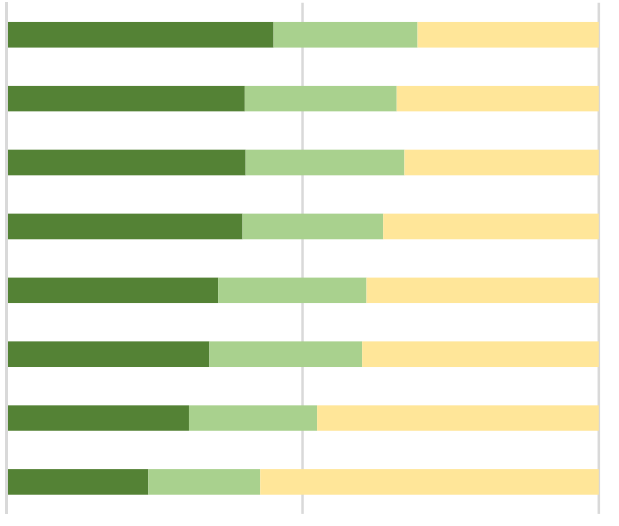

$0 \%$

$50 \%$

- Contribution score (51-100), positive change, influenced much or very much by PUM

- Contribution score (0-50), positive change, influenced little or some by PUM

Contribution score, no positive change and/or no PUM influence on change

PUM's support was especially appreciated for generating new ideas for investments and business organisation. In various firms, the management counselling resulted in new business ideas that sometimes evolved into business proposals for banks.

'He [the expert] gave us a financial model for the entire business. He drafted a business plan with a budget which we could use to access funding. He helped us to see the plans' potential, and helped us to find organisations from which we could request funding.' (Uganda - Coffee and agriculture)

'[We are] much more organised, able to think more strategically. We were more reactive and are now more proactive. We are much more focused.' (Bangladesh - IT) 
PUM benefited SMEs by sharing technical expertise on production processes and improving knowledge on market requirements. Multiple PUM beneficiaries mentioned the benefits of learning about very specific and concrete technical aspects related to production processes.

'He (the expert) told us, for example, to cover the soil between the plants with leaves to keep it moist. It was simple advice, but we had no clue how important something simple like that could be. It has really worked for us to maintain soil moisture and moisture of the fruit. Also he gave us some recipes for fertilizers that we can mix to try out. He gave us a list of how to compose the fertilizer for the plants we need. Now we have a mixer where we make the fertilizers, and an assistant who is in charge of making those fertilizers.' (Uganda-Coffee and agriculture)

PUM also improved the firms' knowledge about requirements in European markets. For example, in Bolivia this concerned better insight into the demands of tourists regarding accommodations and menus.

'...the expert (amongst many other things) advised me to put fewer beds per room because European tourists are used to this. He also recommended that we have customers fill in a small satisfaction survey.' (Bolivia Tourism.)

The data confirm the assumption that PUM helped to improve SMEs' knowledge practices. The distribution of PUM's contributions to change in terms of knowledge and practices presented in figures 4.2 and 4.3 are very similar. Additional correlation analyses show that contribution scores for changed knowledge and practices are closely related in each area of business management, ${ }^{5}$ and this relationship is robust when initial business size, year, access to finance, gender of the owner and country factors are kept constant through econometric analyses. These findings confirm the existence of an impact pathway from perceived changes in knowledge to changes in practices, as shown in the theory of change.

\footnotetext{
${ }^{5}$ Correlation coefficient $>0.6$ for each area.
}

PUM's perceived contribution to a change in knowledge and practices is positively associated with the visible adoption of business practices. The PRIME surveys ask businesses whether they have adopted any of 10 different business practices concerning financial management, marketing, quality, etc. ${ }^{6}$ We tested the correlation between the change in the number of improved business practices adopted by firms in a year and the average PUM contribution scores for knowledge. We find that when contribution score for knowledge is 100 (positive change in knowledge and very much influenced by PUM), the firms adopt 1 new technology. We present our findings in figure 4.4. This figure indicates that there is substantial variation in the adoption of these 10 business practices; some businesses (38\%) adopt these business practices while others un-adopt (15\%) them (negative changes in adoption of business practices).

PUM's contribution to change in knowledge is significantly and positively associated with the amount of new business practices adopted. When firms indicate in their self-assessment that PUM has very substantially contributed to a change in practices, this is also reflected in the on average higher adoption of a new practice. These relationships are robust after keeping firm size, country development, ease of access to finance, year (controlling for business cycles) and region, and sector characteristics constant through a regression analysis. ${ }^{7}$ When PUM's perceived contribution to changes regarding practices increases, this is associated with the adoption of more good business practices. ${ }^{8}$

\footnotetext{
${ }^{6}$ This index is the summation of 10 business practices: the company has statements verfified by control outside the company (by a certified auditor); the company keeps a financial record through an external firm or specialised software; the company has a marketing plan; the company has a business website; the company has promotionl materials; all employees have a business contract: the company has systems and policies in place to monitor and ensure worker safety; the company has a system to learn about the clients' opinions of its products and services; the company has a safety; the company has a system to learn about the clients' opinions of its products and services; the company has
documented quality assurance system; and the company has a system to monitor the effects on the environment. 7 We use these baseline characteristics in the regression as they are available to us and the literature shows that they are important determinants for the adoption of business practices and better business performance.

8 The amount of new business practices adopted is calculated by looking at the difference in the adoption of business practices compared to the previous year.
} 
Figure 4.4 The relationship between perceived PUM contribution to change in knowledge over the past 12 months and the amount of new business practices adopted, when year, cohort, business size, sector and gender of the business owner constant in the regression.

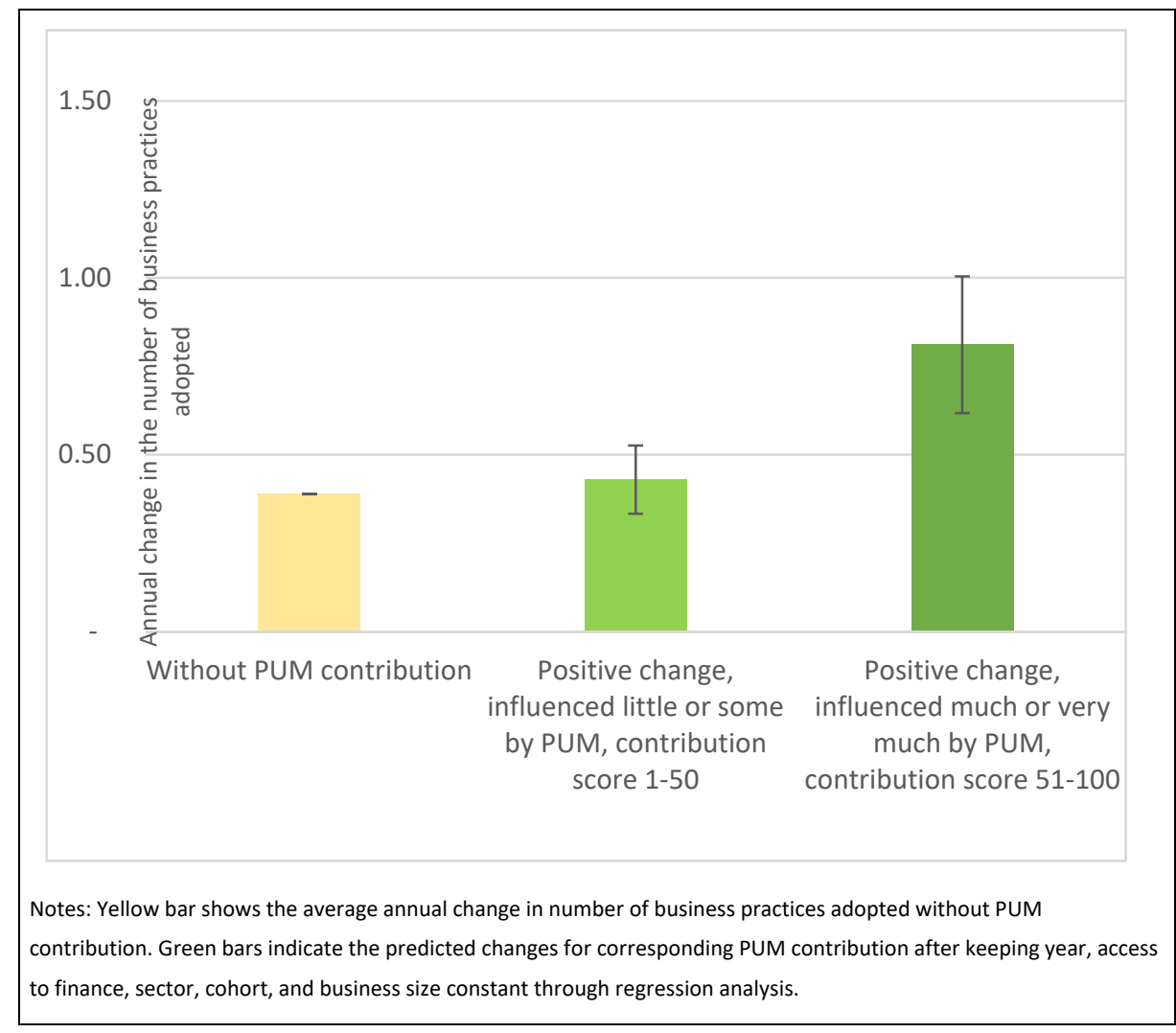

PUM's perceived contribution to practices is homogenously distributed by business size and sectors. Among businesses of different sizes, the reported average contribution score for practices is highest for micro-businesses employing 1-9 employees, and it is higher than the contribution score for small, medium and large businesses, while controlling in the regression for business country, sector, ease of access to finance, year (figure 3.7). However, this difference is not very big.

\section{Case studies show how PUM's support contributes to changes in business} organisation, such as client communication, project management, marketing and HRM. An important effect on business practices has to do with client communication:

'...prompt delivery, also of the pre-shipment sample, turned out to be important. Moving fast is important, so they work with you and not with your competitor. Fast correspondence to maintain the relationship with the buyer is crucial. I respond to my e-mails every day now.' (Uganda-Coffee and agriculture)

Small enterprises often need a qualitative upgrade of their internal management or governance structure. For example, PUM has provided support to firms that were having problems with the inter-generational takeover of family-owned business by suggesting ownership models and investments plans. Some firm owners introduced mid-management, for example for better human resource management. Several firms indicated that the advice to hire a person responsible for HR and recruitment was a key learning point:

'PUM helped me to recruit a manager. I never thought I would pay such high salaries for skilled people. But now I realise that it really helped me to let my company grow.' (Bangladesh - IT \& outsourcing)

Aside from the technical improvements in the production process, several firms supported by PUM indicated that the missions also helped them with a range of general business practices, such as business strategy, project management and marketing:

'I am good at managing the technical things, now l've learned how to manage the business side. [...] [The expert] advised me to get marketing people on board to further develop the business.' (Bangladesh - IT)

In a similar vein, a number of interviewees also indicated that PUM's support had helped them to approach external sources of funding and raise capital to expand: 
'He [the expert] gave us a financial model for the entire business. He drafted a business plan with a budget which we could use to access funding. He helped us to see the plan's potential, and helped us to find organisations from which we could request funding. I ended up using the business plan to get funding from a large donor organisation. Because of that funding we are now seriously expanding one of our products.' (Uganda - Coffee and agriculture)

A typical support activity is the selection of appropriate machinery. The expert uses his network to acquire suitable but low-cost machinery to address important processing bottlenecks.
'We were given [the advice] to purchase a special machine... The machine would allow us to have an area specifically dedicated to organic products. ... We expect the expert to visit us again as soon as the new machine arrives.' (Peru - Natural ingredients)

Selecting the appropriate machinery is not always a success, as this quote from another interviewee illustrates, where a well-intended gift proved costly for the firm.

'The expert said he had found the perfect machine, and he was going to send it to us. Although we knew it was a used machine, we were very happy because it would be free. However, afterwards we had to complete a formality with customs, and in the end the costs seemed higher than it would have cost to acquire a machine directly. However, it was not made from stainless steel, and it was rusty.' (Peru - Natural ingredients)

Figure 4.5 PUM's perceived contribution to practices by business size, when the business country, sector, ease of access to finance and year are kept constant at mean levels

\begin{tabular}{|c|c|c|c|c|}
\hline Dashed lines ar & ence it & & & \\
\hline$\ddot{\pi}$ & 45 & $i$ & & \\
\hline ๗ & 40 & & & \\
\hline$\stackrel{\leftrightarrow}{u}$ & 35 & & + & 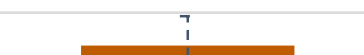 \\
\hline$\stackrel{\frac{n}{0}}{\frac{0}{\alpha}}$ & 30 & & & \\
\hline 胥 & 25 & & & \\
\hline$\overline{\mathrm{E}}$ & 20 & & & 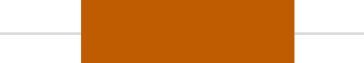 \\
\hline$\frac{0}{8}$ & 15 & & & \\
\hline 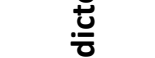 & 10 & & & \\
\hline$\frac{0}{2}$ & 5 & & & \\
\hline & 0 & & & \\
\hline & & Micro, 1-9 & Small, 10-49 & Medium and large, 50+ \\
\hline
\end{tabular}


Figure 4.6 PUM's perceived contribution to practices by sector when the business country, size, ease of access to finance and year are kept constant at mean levels

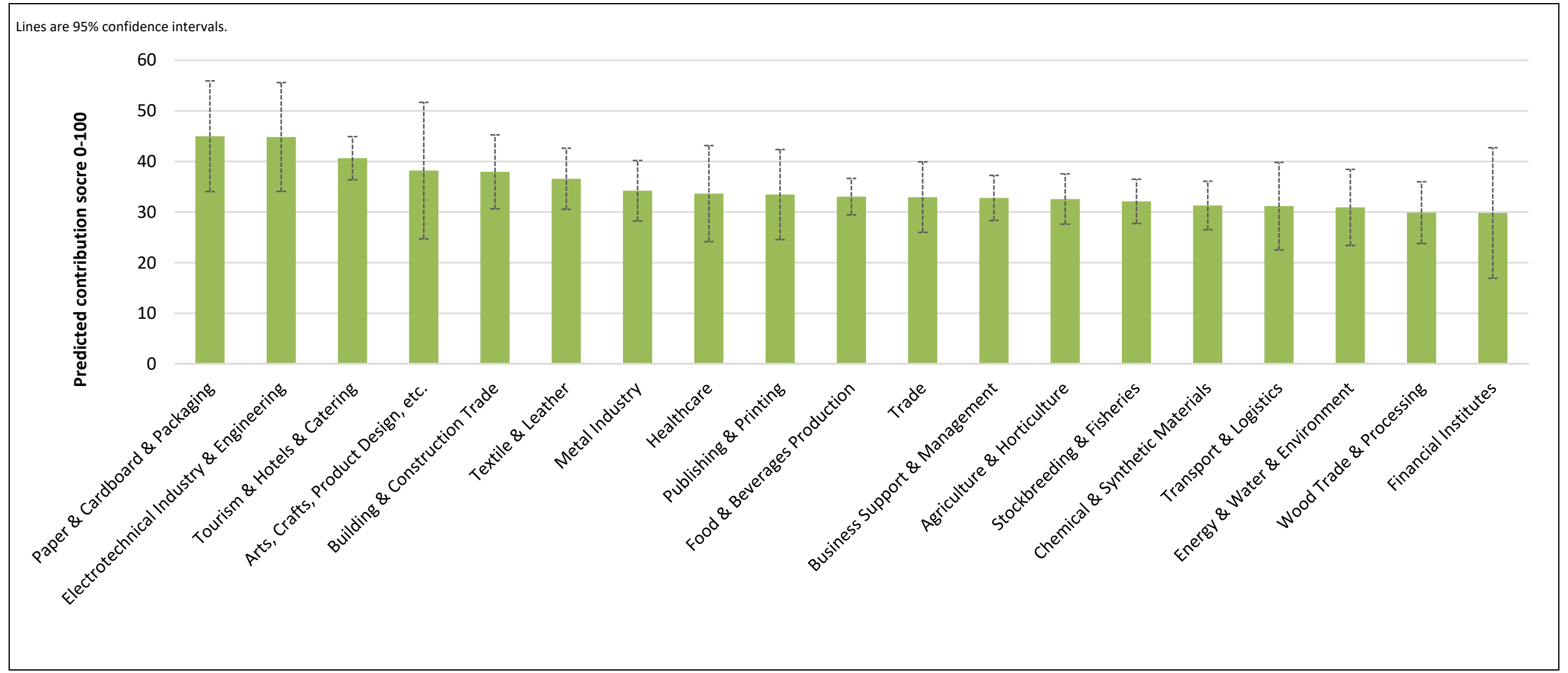




\section{Chapter 5: PUM's contribution to SME performance}

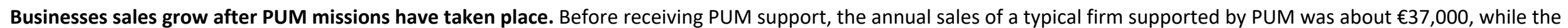
average company employed 29 employees. After PUM provided support, the sales of a typical company increased by about $€ 11,000$ ( $34 \%$ ) when compared to sales before PUM provided support -- keeping the year, sector, country fixed effects and the year of the PUM mission constant in the regression - and our econometric analysis shows that this increase in sales is statistically significant at a $90 \%$ significant level.

Figure 5.1 (Predicted) Sales and employment for a typical PUM company before and after PUM support, after keeping year, cohort, sector, business size and gender of the business owner constant

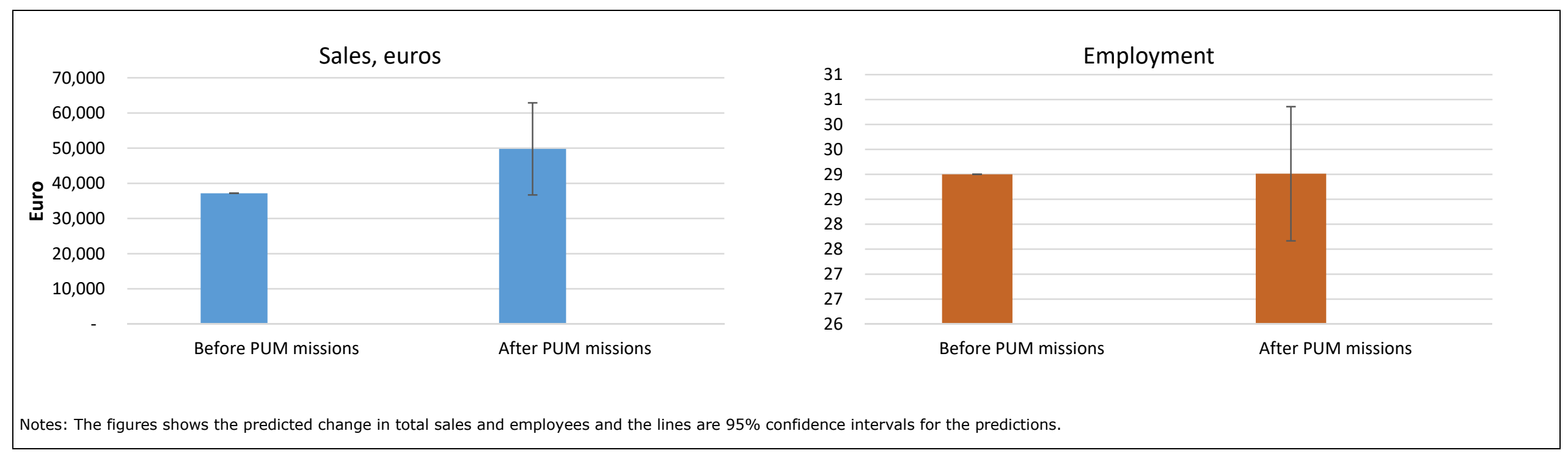


The effect of PUM's support on employment varies according to the focus of the missions. Overall we do not observe a significant increase in the employment levels after PUM missions have taken place (figure 5.1). On one hand, the missions that focus on efficient ways of organising the business increase employment in the business by $33 \%$ (ten employees) (figure 5.2). On the other hand, the missions that focus on financial management reduce employment by $18 \%$ (five employees). These results may imply that PUM missions that focus on efficient ways of organising the business help firms to organise the business better so that they can expand their businesses with new employees. However, the missions on financial management target companies that have financial problems and have to cut their costs.

Figure 5.2 PUM employment effects by mission focus after keeping year, cohort, business size, sector and gender of the business owner constant

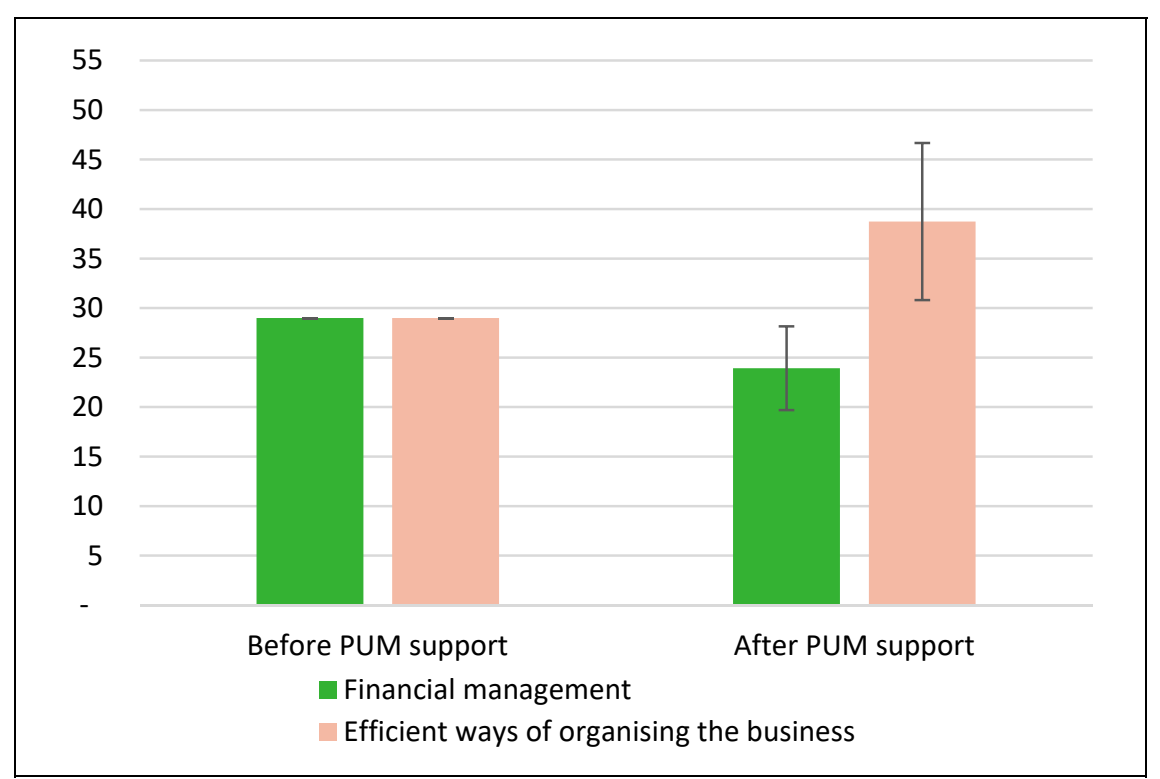

Figure 5.3 Predicted percentages of businesses by change in profits relative to last year in 2016 (2017) and average PUM contribution to change in practices in 2015

(2016), econometric estimates after keeping year, cohort, business size, sector and gender of the business owner constant in the regression

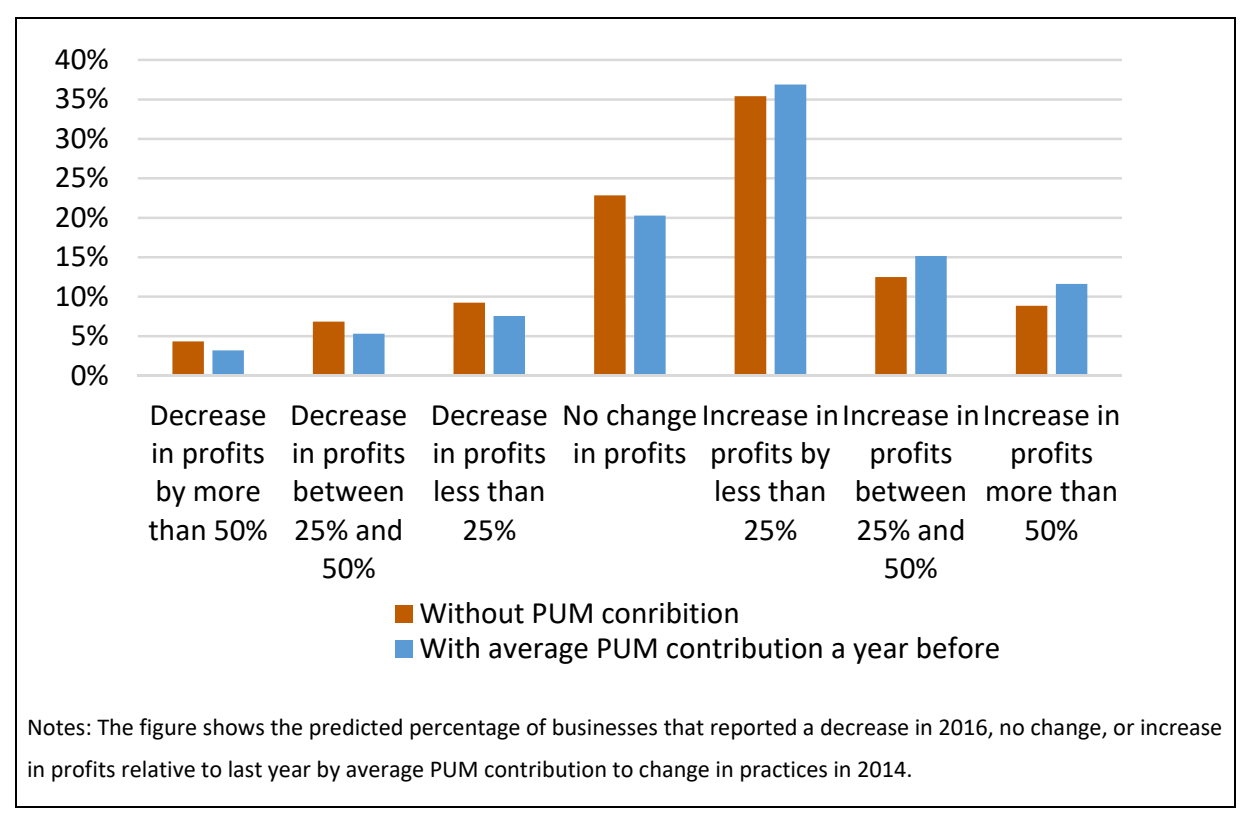

PUM missions contribute to profit growth and increase in sales. Our econometric analysis shows that PUM's average perceived contribution to change in practices and the reported change in profits are positively associated, after keeping sector, country risk, trust and access to finance factors constant. The percentage of SMEs that report an increase in profits (by less than $25 \%$, between $25 \%$ and $50 \%$, or more than $50 \%$ ) is on average $2 \%-3 \%$ higher with PUM's contribution on practices than without PUM's contribution (figure 5.3).

Econometric analysis shows that there is a positive correlation between PUM's contribution to change in terms of efficiently organising the business and business sales. We find that the average PUM contribution to efficient business organisation is 
associated with a sales growth of about $20 \%$ - given that the annual sales of a typical (median) firm supported by PUM is about $€ 37,000$ (please see the left panel of figure 5.1). PUM's contribution to sales growth translates into an annual sales increase of about $€ 7,400$ for the median SME.

Several of the supported firms indicated in the case study interviews that the expert missions had contributed to their firm's performance. When we analyse the performance of the firms by country, we observe a diverging outcome pattern, with some countries and sectors having, on average, a larger growth rate of employment and/or sales. One Ugandan exporter noted a huge effect on sales.

'The expert would categorise his suggestions: immediate ones and those that take effort and time. Sometimes we could not keep pace with the suggestions. However, in his return visits he would notice improvements. For example, he helped us raise our revenues by more than 50\%.' (Ugandacoffee and agriculture)

Another example is the narrative of a fish-breeding firm in Indonesia, which mentions that it was shown better techniques for reducing mortality rates among young fish. Learning these techniques reportedly enabled the firm to increase both production volumes and total profits.

Support does not always improve business performance. PUM's interventions are not always successful in boosting a firm's performance. During the cases studies, several firms indicated that the expert that was dispatched did not have the specific knowledge or expertise to help the firm with the particular problem it was facing. In such cases, no improvements in practices and subsequent firm performance were achieved. Furthermore, some firms indicated that despite the expert's useful suggestions, they were still unable to implement the improvements, because financial constraints prevented them from buying a machine that the expert had recommended, for example.
There is huge heterogeneity in the change of sales following a PUM mission in terms of country development level, business size, gender of the owner and sectors. The column in figure 5.4 shows the average change in sales after PUM provided support. The estimates vary greatly between groups.

Figure 5.4 Sales before and after a PUM mission by sectors, business size, country development level and gender of the business owner Regression analysis after keeping year, cohort, country, sector, business size and gender of the owner constant within the subgroups

\begin{tabular}{|c|c|c|}
\hline Subgroups & $\begin{array}{l}\text { Sales before PUM missions, } \\
\text { EUR }\end{array}$ & $\begin{array}{l}\text { Estimated change after PUM } \\
\text { mission(s) (\%) }\end{array}$ \\
\hline \multicolumn{3}{|l|}{ Sectors } \\
\hline Agriculture \& horticulture & 14,655 & 32 \\
\hline Food \& beverages & 20,000 & 48 \\
\hline Tourism & 59,843 & 98 \\
\hline \multicolumn{3}{|l|}{ Business size } \\
\hline Micro (1-9 employees) & 30,854 & 8 \\
\hline Small (10-49 employees) & 31,846 & 26 \\
\hline $\begin{array}{l}\text { Medium and large (50+ } \\
\text { employees) }\end{array}$ & 52,815 & 44 \\
\hline \multicolumn{3}{|l|}{ Country income group } \\
\hline $\begin{array}{l}\text { Least developed \& low } \\
\text { income }\end{array}$ & 10,950 & 61 \\
\hline Lower middle income & 60,526 & 25 \\
\hline \multicolumn{3}{|l|}{ Gender of the firm owner } \\
\hline Female owned & 50,000 & 61 \\
\hline Male owned & 20,065 & 30 \\
\hline
\end{tabular}

Notes: Column 1 reports the sales of a typical firm in a corresponding subgroup (calculated by $\exp (\operatorname{In}($ sales)). Column 2 report reports the estimated change after PUM missions after keeping other factors constant. 
Sales and employment growth is stronger in the tourism \& catering sector than in the agriculture $\&$ horticulture and food $\&$ beverage sectors. Figure 5.4 compares the performance of SMEs from the agriculture \& horticulture, food \& beverage, and tourism \& catering sectors before and after PUM expert visits through an

econometric analysis that keeps the year, sector, country, cohort factor, gender of the owner and initial business size constant. ${ }^{9}$ The sales for a typical (median) tourism and catering sector SME, which is about $€ 58,000$ before PUM missions, doubles after PUM missions, and employment in this SME increases by $10 \%$, from 24 to 26 . The increase in sales of SMEs in the food \& beverages and agriculture \& horticulture sectors are about $32 \%$ and $48 \%$ after PUM missions; however, in both sectors, the increase in sales is not statistically significant.

PUM missions are more successful at improving the sales performance of businesses in least-developed countries. Figure 4.4 compares the sales performance of firms from least-developed and lower middle-income countries before and after firms are visited by PUM missions. In the least-developed countries, PUM support results in a more pronounced sales increase in terms of percentage. After firms are visited by a PUM mission, the sales of a median PUM firm from a least-developed country increase by $61 \%$ and about $€ 7,000$, compared to the sales before PUM missions.

\footnotetext{
9 We focus on these sectors because we have a sufficient number of observations to conduct the analysis only for these sectors.
} 


\section{Chapter 6: Enabling factors for effectiveness of PUM support}

The preceding chapters focused on the average effects of PUM's support to SMEs. The data show that there is a wide heterogeneity of effects. The effectiveness varies for different types of firms and depends on the conditions in the country and the sector. There are region-specific challenges that sometimes make it difficult to optimally use PUM support. However, in PUM's case, the implementation of the support seems even more important. The effectiveness of the support depends to a large extent on the qualities of the expert, the timing of the mission, and the communication between the expert and the SME manager.

'The impact of the PUM expert's first visit to our hotel, which we had just opened, has been tremendous. For example, the importance of client orientation and the quality of the personnel. However, it was less successful in the Chamber of Hotels. PUM sent a chef when we wanted to organise something [with the members] about business administration. (Bolivia-Tourism)

Language can be a barrier to effective communication. The lack of (advanced) Spanish-speaking experts is mentioned by both SMEs and local representatives as a major issue that impacts the effectiveness of PUM experts in Latin America (Peru and Bolivia). The fact that most of the experts do not speak Spanish is a reason for SMEs to wait before applying for a second mission. Nevertheless, many firms indicate that they would like to have a follow-up mission, which indicates that, in spite of this language problem, most of them consider the missions useful. Sometimes the language issue also results in the designation of someone that is fluent in English but not necessarily the right person in the SME to implement the recommendations.
"I [who runs a travel agency plus hotel] would like to be involved in the CBI courses but [another staff member] would benefit more from them. The problem is the language. As for PUM's advice for the restaurant, I needed to contract a translator to make him work better with the chef and cooking staff.' (Bolivia Tourism)

Important enablers of PUM's effectiveness are the business support organisations. BSOs work to improve the business environment and develop public sector policy and investment programmes. BSOs are important platforms that PUM can use to create demand for its missions. For example, in Peru the country coordinator visits relevant BSOs twice a year to discuss potential collaboration between BSOs and PUM experts. This creates opportunities for concentrated support, especially with sector-specific BSOs. This can result in collaboration where PUM experts provide support to the different firms operating in the sector facing similar challenges.

In Bolivia, PUM provided support to several BSOs in the tourism sector through these platforms:

'We made a plan to work with these platforms, together with $C B I$, to support smaller hotels through seminars and training in a three-year programme. We attached a price tag to it and [we experienced that] people were unwilling to pay the required financial contribution. We hope that with some tweaking, such as lower contributions and support for a shorter training period, it will eventually take off.' (Bolivia - Tourism)

Another key enabler is access to finance in order to change business practices. In most case countries, firms indicated that it was quite challenging for them to obtain bank loans and/or investments, typically because the local financial system is fairly underdeveloped. 
'It's okay to advise someone how to do laundry, but if you don't have soap and water it's not much use. There should be funds available to use the tools that the expert suggests OR they should think of suggestions that fit the business means/resources so that you can use it.' (Uganda-Coffee and agriculture)

Most firms indicated that the local market for consultants did not offer persons with the same skills as the PUM experts had. In most countries there are some other organisations that provide similar services for free. For example, in Indonesia, the Japanese development organisation JAICA provides business development services, albeit mostly focused on larger exporting firms. Similarly, the Indonesian government provides training. Also in Uganda, some firms indicated that they could source similar free support from other donors. When firms needed to pay for the expert, as is formally required in the follow-up missions, many smaller firms, for example in tourism and IT, stated that they would not have the capacity/willingness to pay for it. We noticed that PUM follow-up missions in these sectors take place in relatively larger and capitalised firms.

'The expert did a very fine study on financial costing and we know that if we need the expert again we would have to pay approximately US\$2,000, but we have not been able to do it yet.' (Peru - Natural ingredients)

The cost of a mission in the tourism sector is relatively low, as most hotels can offer free beds. For other firms the costs add up quickly, with the firm having to foot accommodation costs, plus the contribution to the second mission. This may explain PUM's relatively large presence in the hotel sector. Because lodging costs are low for hotels, the support to this section of the economy seems disproportionately high. It is not necessarily the sector with most potential for direct job creation (although it may be in terms of indirect jobs) or sector innovation.

The cost of a mission is an impediment for the - more targeted - second missions. The cost of a second mission ( $€ 700)$ is often an impediment. Many experts and firms consider follow-up missions to be more effective in changing business practices than the first mission, which is usually limited to a diagnosis of the problem. As a result of the cost, the opportunity to have a second, more targeted mission is sometimes missed.

This explains why the focus of follow-up missions is often on relatively larger firms with multiple support missions. We encountered an illustrative example in Uganda, where PUM supports a successful enterprise that clearly benefits from PUM's support, even though it is not what one would consider the usual target group of development cooperation.

'We are a firm that grows flower stems and vegetables. We have 650 full-time workers. We export 220 million stems. [Soon] our PUM expert will visit us again. For the vegetable production. The costs of an expert with knowledge on vegetables is too high for us. He is the father of a friend of mine. PUM is a good programme. He gives intensive support. He has much experience in Congo.(...) After the first visit the expert has a general understanding of how the firm works and what the possibilities are. After the second visit he knows why some things work or do not work. From the third visit onwards he knows what really matters and what to do about it. Then the suggestions really begin to help.' (Uganda-Coffee and agriculture)

We found several firms where Dutch-nationality investors used PUM's support to grow. Though compatible with other Dutch PSD support (e.g. RVO, the Netherlands Enterprise Agency), one could question the relevance of this support to relatively wealthy firms from the perspective of development cooperation.

The spillover effects are highly case-specific and most clearly visible in agricultural processing firms. The agricultural processors and exporters (for example in Peru and Uganda) obviously have an upstream effect regarding farmers' access to markets. Some processors are actively working with their suppliers, though, and due to competition with other buyers, there are limits to their willingness to invest in them. 
'We do a lot of field work with the farmers. We invest in farmer field schools, and in the certification of crops. The problem we face is that after so much work sometimes the collectors come and make the farmers an offer to buy their production and they do not wait or earn a few cents more, they sell them and leave our company unsupplied' (Peru - Natural ingredients)

The spillover effects from the tourism sector in Bolivia are mainly in the top-end of the food services and in the transport sector. The effect on local poverty alleviation appears modest at most, and the effect on rural areas, even on rural tourism development, is likely to be very small. Furthermore, spillover effects can also occur through the transfer of knowledge from supported to non-supported firms. This is illustrated by the example of a PUM-supported firm in the aquaculture sector in Indonesia that received expert advice about fish-breeding practices and consequently took the initiative to share this newly acquired knowledge with other small firms and local fish farmers in the region, without charging fees. In addition, this PUM beneficiary also provided consulting services to a larger fish farm in the region.

Both PUM staff and policymakers consider more coordination with other Dutch private-sector support organisations to be an important enabler of effectiveness. Several local representatives of PUM considered the relative isolation of the provided expert support as one of the areas that could be improved.

"What would help is to have an "airport" where local experts can meet international consultants. The Bolivian experts would be permanent and would need to know what the international consultant has done in the mission to give follow-up.' (Local representative Bolivia)

The network of Dutch development NGOs in the country would seem to be an avenue for accomplishing this idea. Organisations such as ICCO, HIVOS, CORDAID, NOVIB, AGRITERRA, CBI and SNV are likely partners. However, many of these organisations have their own experts, and sometimes compete in the market of business service provisioning. However, in several cases there is a demand for PUMs specialised expertise and a peer-to-peer model. But coordination is not easy.

'... the issue is that [another Dutch development organisation] does not see PUM as a complementary ally but as a competitor. They have experts that need to be paid, while PUM works for free.' (Local representative La Paz).

However, we found several cases where the PUM expert used the wider available support and established contact with other Dutch development organisations or national ministries. Of course, this is more apparent in the support provided to (BSOs, such as this Ugandan consultancy firm.

'[For our conference] we are trying to get sponsorship from big industry players. I want to talk to the Dutch embassy about it as they seem enthusiastic. The PUM consultant put us in touch with them. That should happen soon. The embassy can help with regional coordination and partnerships. (..)

The consultant also helped us with our difficult relationship with the ministry. They were afraid that we would take over their role. He even wrote to them. I tried as well, but his letter made more of an impression on them than mine ever did.' (Uganda - Coffee and agriculture)

We did not find many joint initiatives by CBI and PUM. Coordination between CBI and PUM was mentioned only in the Peru and Bolivia cases. The appropriate target group for PUM experts seems to be in relatively smaller firms than in CBI, or in complementary sectors (e.g. PUM's support to restaurants and hotels and CBI's support to travel agencies). This complementarity seems the most likely form of synergy that could emerge, and it could provide a model for the integral support of several RVO instruments for sector programmes. This would also enable access to the complementary funding modalities needed to implement some of the business strategies (e.g. in FOB garment production, sustainable aquaculture, etc.). In Peru a firm mentioned the synergy of support: 
'We learned about PUM through CBI's support. They recognised that there were technological flaws and therefore we needed specialised support. With PUM we were able to address our more technical problems and with $C B I$ we work more on articulation to markets.' (Peru - Natural ingredients)

The local representatives interviewed are highly committed to their work. They visit BSOs to talk about PUM and create demand for expert missions. When possible, they try to meet the expert at the airport.

'I used to pick them up at the airport. Nowadays I don't anymore because there are too many of them. On the way back we used to discuss whether a follow-up mission would be needed.' (Local representative in Lima)

The financial incentive for local representatives is to increase the number of missions, and not necessarily improve the quality of missions, or the number of follow-up missions. They get paid to successfully match a firm and a PUM expert in a process in which they do not have much influence on the type of expert that will be selected. They therefore need to be trusted by the firms; an unsuccessful mission can jeopardise this personalised relationship of trust.
We found that PUM's local representative is not briefed about the commitments that the firm made with the expert due to the confidentiality of the business data. The experts report to the country coordinator in the Netherlands, not to the local representative. This sub-optimal information regarding follow-up is attributable to confidentiality issues, in order to reduce the risk that the local representative use this business knowledge to take economic advantage or inform competitors. It seems unlikely that curtailing this risk will compensate for the reduced in-country learning and limit the effectiveness of PUM support, especially the number of more targeted and apparently more successful follow-up missions. 


\section{Chapter 7: Conclusions}

The intervention logic. PUM's approach is based on the assumption that its senior experts provide useful knowledge to firms, which in turn helps these firms to adopt better practices and increase their sales, profits and employment - and ultimately contribute to sustainable and inclusive economic growth. We need evidence to support this claim. ${ }^{9}$ The PRIME research makes it possible to test these assumptions. In this section we reflect on the main results and how these relate to PUM's policy focus and private-sector development in developing countries more generally.

PUM positively influenced both SME knowledge and business practices. The findings from the PRIME research provide ample support for the assumption that, overall, PUM experts make a positive contribution to the business knowledge and practices of firms. Almost all firms (90\%) report at least one area in which PUM contributed to knowledge. This conclusion corresponds to previous findings ${ }^{10,11,12}$ (McKenzie and Woodruff, 2014; Piza et al., 2016; Grimm and Paffhausen, 2014).

The increased knowledge of SMEs results in better business practices. The firms attribution of PUM to their business knowledge is positively correlated with objective types of business practices, such as keeping financial records. When firms state that PUM contributed substantially (higher contribution score), this is also reflected in a higher rate of improvement in these objective practices.

PUM's support helps to increase sales and profits. Most studies find that training and advisory services, such as bookkeeping and business planning, had positive shortterm effects on firms' practices. However, fewer studies find that these programmes have positive effects on business performance ${ }^{13}$ (McKenzie and Woodruff, 2014). PRIME research shows that the sales of PUM firms increased following PUM missions, compared to sales before PUM missions. After the completion of a PUM mission, the sales of a median PUM-supported firm increased by $34 \%$. Also supporting this evidence is a positive significant correlation between firms' perception of PUM's contribution to their business practices and objective measures of firms' sales and profits.

Not every type of PUM mission has a measurable effect on employment. We do not observe an overall significant increase in employment levels after PUM missions have taken place. The missions that focus on efficient ways of organising the business increase employment, but the missions that focus on financial management reduce employment. PUM support, therefore, does not always increase employment. The lack of an increase in employment following PUM missions combined with an overall increase in sales implies that PUM's support did help to increase labour productivity. This result corresponds with recent findings which indicate that the effect on employment seem to come last, and non-existent or negative effects on employment can even be good news because this helps firms to become more profitable. ${ }^{14}$

PUM's support has a varied effect on different types of firms. The effects of PUM's support are not the same for all firms. PUM's interventions contribute more to firms' knowledge and business practices in less-developed and low-income countries and in the trade and manufacturing sectors. This finding corresponds with the fact that firms in less-developed countries typically have lower levels of business knowledge and practices to start with, so the marginal benefits of PUM's support are greater there. A focus on less-developed countries is likely to increase the impact on knowledge and business practices.

PUM's support complements other kinds of business support. The case studies indicate that commercial consultancy services similar to PUM's are generally not 
available locally at affordable rates. This supports the assumption that this type of international support is relevant and is additional to other support provided to firms in these countries. ${ }^{15}$ Furthermore, most firms indicate that there are few donors, NGOs and government agencies providing similar support, which further strengthens our impression that PUM's support is additional to the existing market. To summarise, these results support the notion that PUM's activities are complementary, which is a key principle for the ministry in the allocation of PSD support.

Multiple missions are perceived to be more effective. The case-study research found that most firms that were visited by multiple missions consider these follow-up missions to be increasingly effective. The first mission essentially improves knowledge and suggests new ideas, but the follow-up missions are considered to be more effective in changing business strategies.

Local representatives may play a more active role after the first mission in checking commitments and preparing the ground for follow-up missions. The financial incentive for local representatives is to increase the quantity of missions not the quality. The contribution for a follow-up mission could be based on the turnover or asset base of the supported firm, and need not be uniform for all firms that apply for a follow-up mission. This would rebalance the current financial incentives for well-off firms that apply for follow-up. 


\section{Chapter 8: Recommendations}

This chapter provides recommendations for PUM in four different categories The PRIME research partnership has assisted PUM in assessing its support to SMEs, exploring the conditions that help or constrain that support, and exploring for what type of firms this support is most effective. This chapter provides recommendations for PUM in four different categories: (1) suggestions on how different contexts influence the effectiveness of PUM support; (2) recommendations on how the design of the PUM missions can influence their effectiveness; (3) proposals on how to improve the effectiveness of PUM missions in contributing to intended outcomes and impacts, and (4) suggestions on how to further improve PUM's monitoring system by including elements that might further strengthen PUM's impact evidence.

First, the context in which PUM missions take place partly determines their success. Region, country, sector and SME size all influence the effectiveness of PUM support Our findings show that PUM interventions contribute more to firms' knowledge, business practices and sales in less-developed and low-income countries than in lower middle-income countries. A focus on less-developed countries is therefore likely to increase PUMs impact. Less certain is the degree to which increased sales would also translate into increased firm performance in the long run.

The data show that PUM support is more effective in contributing to increased sales of companies in the industry and services sector than in the agricultural sector. $A$ focus on these sectors could therefore also increase the impact of PUM's missions. Finally, the data show that the size of the companies that are targeted by PUM missions matters for its effectiveness. The evidence shows that targeting medium and large companies (50+ employees) is more likely to contribute to higher sales growth than targeting small (10-49 employees) or micro (1-9 employee) companies. PUM could therefore apply its policy to focus on larger companies more strictly.
Second, improvements in the design of PUM missions could increase their impact, such as better SME-expert matches, improved communication and more follow-up. Findings show that the PUM expert does not always have the right knowledge to assist the SMEs with their problems. Several solutions could help solve this issue: (1) focusing on high-quality intake procedures, (2) making sure that local representatives have sufficient sector knowledge to judge applications, and (3) organising more interaction between local representatives and experts to facilitate a better match.

\section{Improving PUM's communication with local representatives and broadening their} incentives can enable them to better support the PUM missions locally. Local representatives are sometimes owners of businesses that compete with SMEs supported by PUM. Therefore, they are not briefed about the commitments between experts and SMEs. PUM could explore whether part of the information on the type of support could be shared with the local representative (after consent by the SME) to allow him/her to provide better follow-up support and prepare the conditions for a second mission. Moreover incentives could be explored to reward representatives for high-quality missions, by paying for the time they invest, for visiting more remote areas or facilitating sector workshops.

Expanding the number of follow-up missions and improving after-care upon completion of the mission is expected to increase PUM's effectiveness. Our findings show that many experts and SMEs consider follow-up missions to be more effective in changing business practices than the first mission. PUM could provide incentives to have more follow-up missions, for example by using the share of follow-up missions as a key performance indicator. As follow-up missions are more costly, PUM experts could also spend more time on after-care, regularly advising SMEs after their visit. 
Third, PUM could build on proven opportunities to improve the effectiveness of PUM missions in reaching their intended outcomes and impacts. For example, our findings show various ways of increasing PUM's impact on the knowledge levels of SMEs. Case studies show the benefits of cooperation with other Dutch development NGOs for optimal business service provisioning. Several beneficiaries created spillover effects by sharing lessons learned with other firms; this behaviour could be encouraged by incentivising SMEs to share their knowledge with others. Finally, case studies have shown the importance of language in transferring knowledge; especially in Spanish-speaking countries it is recommended that PUM experts speak the language - and if they do not, incentives are provided to hire a good interpreter.

The results from this study provide insights in how PUM could further increase its impact on the business practices of SME's. Supported companies indicate that in order to translate the knowledge acquired in a mission into practice, they need better access to finance. Over half of the supported companies indicate that it is hard (34\%) or very hard (22\%) for them to finance their business activities. PUM could expand its current efforts to link firms requiring capital with Dutch financing institutions. Our findings also show that there is relatively little focus in PUM missions on helping firms adopt more sustainable business practices. PUM could think of ways to help their experts to include CSR and sustainability in their missions. Current pilot projects by PUM that use a CSR tool developed by CBI might help to achieve this goal; another way would be to provide PUM experts with training on CSR and sustainability.

Our findings also point to important barriers and enablers in reaching intended outcomes, such as increased profitability and employment. An analysis of the PRIME dataset shows that not every type of PUM mission has a measurable employment effect. PUM could think of shifting more of their activities to sectors or types of missions with higher potential for job creation and sector innovation, or reconsider its theory of change. In general, there is a need to reflect on impact pathways for increasing employment, and the type of jobs - productive jobs, green jobs - that PUM aims to help create. Our findings do show that PUM helps firms to become more profitable. To further enhance profitability, PUM could start to monitor how the increase in profits as a result of PUM's support is spent: is it invested in labour-saving technology, expansion, hiring more people or raising wages?

Finally, PUM could complement its current monitoring system with several elements to further strengthen the evidence base for PUM's contribution. This report has shown how the PRIME survey helped to collect information on PUM's contribution to knowledge, practices and profitability. Adding some of the key questions from the PRIME survey to PUM's regular monitoring system could help track the progress PUM is making in achieving its objectives under different conditions. The current monitoring system should also continue to collect this information from supported firms several years after mission are completed.

Regular communication and attractive outputs can help to fuel strategic decisions, while creating ownership of the data collection process within the organisation. The experience of PRIME shows that regular communication about the findings from the collected data in the form of meetings, workshops and 'sense-making' sessions is needed to make it relevant for strategic decisions. Especially the form in which data are presented - preferably concise and attractive rather than academic - is important for the degree to which findings are taken up. Finally, regular and attractive communication about the findings from PUM's monitoring system - not only among staff but also among experts and local representatives - will help to create the necessary ownership for collecting impact data on a regular basis.

PUM could benefit from using evidence-based pilot projects to test novel approaches to its activities. For example, in relation to its ambition to implement longer missions for fewer firms, it would be useful to design a pilot project to test whether this indeed is more effective in terms of promoting firms' growth. Another example could be to use pilot projects to compare the cost-effectiveness of different ways of bringing knowledge to SMEs, for example for comparing digital knowledge exchange with face-to-face knowledge transfer during missions. What is crucial here is to consider evidence-based pilot projects not just for accountability purposes, but as a useful tool to improve the organisation's overall effectiveness. 


\section{References}

Bamberger, M., 'Introduction to Mixed Methods in Impact Evaluation'. Washington D.C.: Interaction: New York: Rockefeller Foundation. (2012)

Atkin, D., Khandelwal, A. K. and Osman, A. 'Exporting and Firm Performance: Evidence from a Randomized Experiment'. Q. J. Econ. 132, 551-615 (2017).

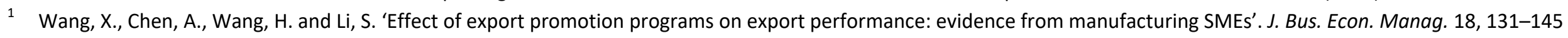
(2017).

1 Bulte, E., Lensink, R. and Vu, N. 'Do Gender and Business Training Affect Business Outcomes? Experimental Evidence from Vietnam'. Manag. Sci. 63, 2885-2902 (2016).

1 Campos, F. et al. 'Teaching personal initiative beats traditional training in boosting small business in West Africa'. Science 357, 1287-1290 (2017).

1 Hong, J. and Lu, J. 'Assessing the effectiveness of business incubators in fostering SMEs: evidence from China'. Int. J. Entrep. Innov. Manag. 20, 45-60 (2016).

1 Bloom, N. and van Reenen, J. (2007). 'Measuring and Explaining Management Practices Across firms and Countries'. Quarterly Journal of Economics, 122 (4): $1351-1408$.

1 Bardasi, E., Shwetlena S. and Terrell, K. 'How do female entrepreneurs perform? Evidence from three developing regions'. Small Business Economics 37.4 (2011): $417-441$.

1 White, H. 'Theory-based impact evaluation: principles and practice'. Journal of Development Effectiveness 1, 271 - 24. (2009)

1 McKenzie, D. and Woodruff, C. 'What are we learning from business training and entrepreneurship evaluations around the developing world?' The World Bank Research Observer 29, 48-82. (2014).

1 Piza, C., Cravo, T. A., Taylor, L., Gonzalez, L., Musse, I., Furtado, I., Sierra, A. C. and Abdelnour, S. 2016. 'The Impacts of Business Support Services for Small and Medium Enterprises on Firm Performance in Low-and Middle-Income Countries: A Systematic Review'. Campbell Systematic Reviews, 2016, 165 (2016)

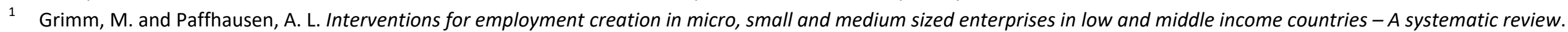
Passau: University of Passau. (2014).

1 McKenzie, D. and Woodruff, C. 'What are we learning from business training and entrepreneurship evaluations around the developing world?' The World Bank Research Observer 29, 48-82. (2014)

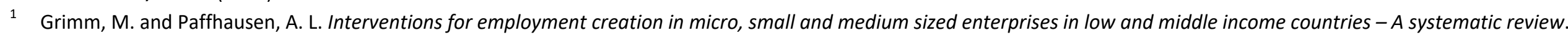
Passau: University of Passau. (2014)

1 Heinrich, M. Demonstrating Additionality in Private Sector Development Initatives: A practical exploration of good practice for Challenge Funds and other cost-sharing mechanisms. London: DCED (2014). 

